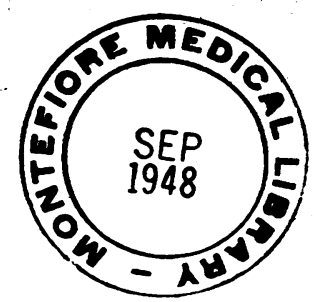

\title{
THE TREATMENT OF PURULENT PACHYMENINGITIS AND SUBDURAL SUPPURATION WITH SPECIAL REFERENCE TO PENICILLIN
}

\author{
BY \\ F. SCHILLER, H. CAIRNS, and DOROTHY S. RUSSELL
}

From the Radcliffe Infirmary, Oxford

(RECEIVED MAY 3, 1948)

INDEX

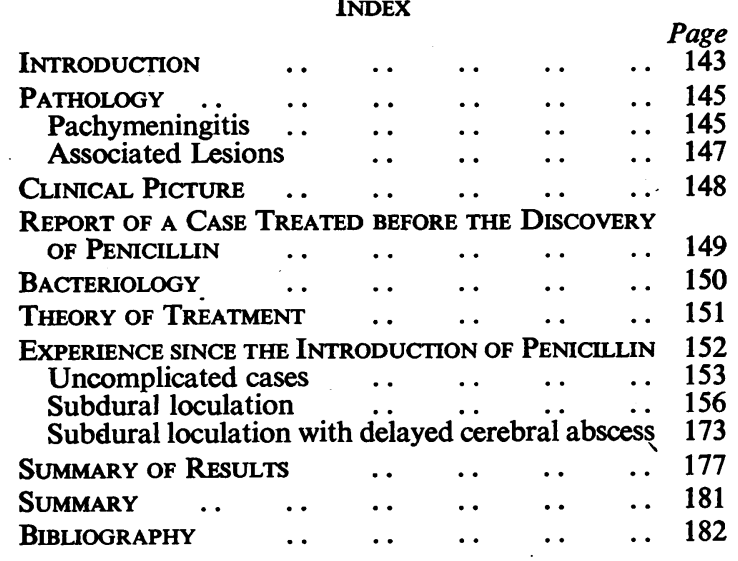

Introduction

In this paper we report four years' experience of penicillin in the treatment of purulent pachymeningitis. Formerly, even after the introduction of sulphonamides, the condition was almost always fatal; since the advent of penicillin seven of our fifteen cases have recovered, and these results should be greatly bettered now that penicillin is freely available and we are beginning to understand the problems of treatment. Excluding cases in which the condition was secondary to cerebral lesions, we have seen in all thirty-three cases of this disease in the last twenty years (Table I).

Purulent pachymeningitis is characterized by a film of pus of variable thickness in the subdural space spreading over part or whole of one or both cerebral hemispheres. It has been termed subdural empyema, subdural abscess, internal purulent pachymeningitis, and various other names. We prefer the term purulent pachymeningitis on analogy with the term purulent peritonitis. As in peritonitis, the pus tends at first to spread diffusely, but then may become closed off in a number of loculated subdural abscesses. As in purulent peritonitis so in purulent pachymeningitis, drainage of the pus at one part of the subdural space in the acute stage may not always prevent its loculation at another part of the subdural space at a later stage. A favourite site of loculation in the peritoneal cavity is in the space between the diaphragm and liver, which is as narrow as the subdural space. In another flat space lined with endothelial cells, the pleural cavity, loculation of pus is also apt to follow generalized suppuration.

Purulent pachymeningitis is usually secondary to

TABLE I

PURULENT PACHYMENINGITIS : SITE OF PRIMARY INFECTION AND DISTRIBUTION OF ORGANISMS

\begin{tabular}{|c|c|c|c|c|c|c|}
\hline $\begin{array}{c}\text { Primary } \\
\text { infec- } \\
\text { tion }\end{array}$ & Strep. & $\begin{array}{c}\text { Strep. } \\
\text { and } \\
\text { Staph. }\end{array}$ & Staph. & Pneum. & $\begin{array}{l}\text { No } \\
\text { record } \\
\text { or } \\
\text { incon- } \\
\text { clusive }\end{array}$ & Total \\
\hline $\begin{array}{l}\text { Para- } \\
\text { nasal } \\
\text { sinus }\end{array}$ & 18 & - & - & 1 & 4 & 23 \\
\hline Mastoid & 3 & 1 & - & - & 2 & 6 \\
\hline $\begin{array}{l}\text { Distant } \\
\text { focus }\end{array}$ & 3 & - & 1 & - & - & $4^{*}$ \\
\hline Total & 24 & 1 & 1 & 1 & 6 & 33 \\
\hline
\end{tabular}
peritoneal cavity, 1 ; tooth and pleural cavity, 1 . 
TABLE II

PASSAGE OF PENICILLIN FROM BLOOD TO SUBDURAL FLUID IN TWO CASES OF SUBDURAL HAMATOMA

\begin{tabular}{c|c|c}
\hline $\begin{array}{c}\text { Minutes after } \\
\text { intramuscular } \\
\text { injection, }\end{array}$ & \multicolumn{2}{|c}{$\begin{array}{c}\text { Penicillin in subdural fluid } \\
\text { units per c.cm. }\end{array}$} \\
\cline { 2 - 3 } units & Case 1 & Case 2 \\
\hline 0 & 0 & 0 \\
2 & 0 & - \\
10 & 0.5 & 0.3 \\
20 & $0.05^{*}$ & - \\
22 & - & 0.4 \\
30 & - & $0.15^{*}$ \\
35 & - & $0.05^{*}$ \\
50 &
\end{tabular}

* Subdural fluid diluted with Ringer's solution.

spreading osteomyelitis of the skull, which is an unhappy sequel in some cases of pansinusitis (Plate I a) and mastoid disease, and otologists have written extensively on the subject (McKenzie, 1913). There has been some confusion about the situation in which the intracranial pus collects. Some of the earlier writers called any collection of pus inside the dura a cerebral abscess, but from their descriptions it is clear that some at least of these were subdural (McKenzie, 1913). The differences between leptomeningitis and pachymeningitis have not always been clearly understood, and pus which is obviously subdural pus of pachymeningitis has been described as " in the subarachnoid space between both hemispheres" (Mair, quoted by Dreyfuss, 1896) or in the " cavum arachniodeum " (Paulsen, quoted by Dreyfuss, 1896). Pus encountered when the dura is opened is usually subdural and not subarachnoid.

The subdural and subarachnoid spaces are quite distinct.* The subdural space usually appears to be empty, but Penfield (1924) showed that in dogs it may contain small amounts of clear yellow fluid. It is bounded by dura without and arachnoid within, is lined with a single layer of endothelial cells, and is a single continuous space over the surface of the brain and spinal cord, except where arachnoid granulations are embedded in the dura. Air passes readily from one end of the cranial subdural space to the other (Plate I b and c). Penicillin passes readily to and fro between the blood stream and any fluids which may accumulate in the subdural space (Table II). The subarachnoid space, on the other hand, is a channel traversed by numerous fine septa and containing cerebrospinal fluid. Air in

* The subdural space is inconspicuous and is not recognized at all by some writers. Thus Logan Turner and Reynolds do not figure it in their diagram of the coverings of the brain (Turner and Reynolds, 1931, Fig. 1). it cannot move freely with alterations of head posture, (Plate II d and e); and penicillin does not pass freely between the blood and cerebrospinal fluid. The arachnoid membrane is a firm barrier between the subdural space and the cerebrospinal pathways, only weakened by the fact that it is pierced by entering and leaving blood vessels, and by the arachnoid granulations which burrow into the dura mater. With these facts in mind it is easy to understand that pus may spread widely in the subdural space without any gross signs of leptomeningitis.

There are several varieties of subdural suppuration, but in this paper we are concerned only with purulent pachymeningitis and those subdural abscesses which are formed when the subdural pus becomes loculated. The reason for so narrowing our attention is that purulent pachymeningitis is a distinct pathological entity which produces a sharply defined clinical picture, and, now that it can be treated successfully, it is important that this should be recognized. Infections of the subdural space are often complicated by infections in other parts of the cranial chamber, and the chain of pathological events in any one case may baffle the 0 clinician. In the cases which we describe the intracranial infection always began with purulent $\Phi$ pachymeningitis which could be recognized clinically even though in some cases it was soon alleviated by penicillin, or otherwise modified by the formation of a loculated subdural abscess, with or without a cerebral abscess. Hence we exclude the following types of subdurál suppuration.

1. Localized subdural abscess secondary to, or arising simultaneously with, a subjacent cerebral abscess.

2. Localized subdural abscess following focal necrosis of the dura, as a sequel to focal osteomyelitis of the petrous or other bones of the skull.

The distinction of these conditions from purulent pachymeningitis is not always possible clinically, especially now that penicillin is proving effective in controlling the spreading type of infection, but nevertheless it should be drawn whenever possible because of its therapeutic importance. In localized subdural abscess intracranial surgical treatment can be limited to the area of the abscess. In purulent pachymeningitis, on the other hand, penicillin instillations of the whole subdural space are often necessary if loculation of pus alongside the falx cerebri is to be prevented.

3. Infected subdural hæmatoma. The common subdural hæmatoma of civilian practice may become infected after operation. Infected subdural hæmatoma may also occasionally arise after a radical ethmoid operation at which the overlying dura has been penetrated (Cairns, 1937, Case 10). This is a condition which may simulate purulent pachymeningitis. 
TABLE III LESIONS ASSOCIATED WITH PURULENT PACHYMENINGITIS (THIRTY-THREE CASES)

\begin{tabular}{c|c|c|c|c|c|c|c|c}
\hline & $\begin{array}{c}\text { Total } \\
\text { cases }\end{array}$ & $\begin{array}{c}\text { Spreading } \\
\text { osteo- } \\
\text { myelitis } \\
\text { of skull }\end{array}$ & $\begin{array}{c}\text { Extradural } \\
\text { abscess }\end{array}$ & $\begin{array}{c}\text { Thrombo- } \\
\text { phlebitis } \\
\text { or sinus } \\
\text { thrombosis }\end{array}$ & $\begin{array}{c}\text { Cerebral } \\
\text { abscess }\end{array}$ & $\begin{array}{c}\text { Severe } \\
\text { lepto- } \\
\text { meningitis }\end{array}$ & $\begin{array}{c}\text { Pulmonary } \\
\text { abscess }\end{array}$ & $\begin{array}{c}\text { Subdural } \\
\text { loculation }\end{array}$ \\
\hline $\begin{array}{l}\text { Sinus } \\
\text { infection }\end{array}$ & 23 & 19 & 12 & 4 & 3 & 6 & 2 & 13 \\
\hline $\begin{array}{c}\text { Mastoid } \\
\text { infection }\end{array}$ & 6 & 4 & 3 & 4 & 2 & - & - & 3 \\
\hline $\begin{array}{c}\text { Distant } \\
\text { focus }\end{array}$ & 4 & 3 & 1 & - & 3 & 1 & - & - \\
\hline Total & 33 & 26 & 16 & 8 & 8 & 7 & 2 & 16 \\
\hline
\end{tabular}

4. Subdural suppuration, or infected subdural hæmatoma secondary to penetrating or non-penetrating missile wounds of the head. Three cases of this condition have recently been described (Cairns and others, 1947, Cases 1, 2, and 12) and it is of interest in connexion with the present study that the predominant organisms were non- $\beta$-hæmolytic streptococci-the same group of organisms, in fact, which cause the purulent pachymeningitis of civilian practice.

\section{Pathology}

At necropsy there are the lesions directly connected with the subdural suppuration, and the associated infective lesions (Table III) which vary from case to case. It will be convenient first to deal with purulent pachymeningitis and its effects, and later to consider the associated lesions.

\section{PaChymeningitis}

At operation or necropsy in the acute stage the subdural space contains free pus which is limited to and more or less evenly distributed over part or whole of one or both cerebral convexities. Though usually thick and creamy, it is easily wiped away from the limiting membranes of the space, leaving smooth surfaces. The leptomeninges may be opaque and there may be, in places, an excess of subarachnoid fluid, but in uncomplicated cases purulent exudate is not present beneath the arachnoid. When the dura is opened at operation a small amount of pus escapes and then the brain, which is usually under raised pressure, plugs the dural opening. Further pus can be obtained by depressing the brain. At necropsy severe herniation of the uncinate gyri through the tentorial opening, or of the cerebellar tonsils through the foramen magnum, indicates the great rise of intracranial pressure.

At a later stage the pus becomes thicker, and fibrinous adhesions develop between the dura and arachnoid ; the surfaces of the dura and arachnoid lose their normal lustre. There is a tendency, too, for the pus to concentrate at certain points, such as alongside the falx (Plate II a), or on the upper surface of the tentorium (Plate II b), or on the diaphragma sellæ. Such loculation leads, still later, to segregation of the pus into abscesses. There is then a corresponding deformity of the adjacent brain. A grey membrane of variable thickness forms on the deep aspect of the dura and, less marked, over the opposing arachnoid. Until it is organized this membrane is shaggy and friable. By organization it is converted into fibrous granulation tissue. The end results of the process will vary macroscopically according to the amount and distribution of the pus. In some areas, where the pus has not amounted to more than a thin film, the subdural space may resume its patency and the dura shows little change beyond a grey, or greyish-brown thickening of its innermost areolar layer. Elsewhere the dura is united to the arachnoid by an opaque yellow lamina of fat-granule cells and this is eventually organized by fibrous tissue, the dura thus becoming firmly fused to the arachnoid membrane. Greater accumulations of pus become loculated to form abscesses (Plate II b).

\section{Microscopical Appearances}

Normal Histology of the Dura.-The cranial dura is composed of two stout layers of dense collagenous tissue, the fibres of the layers being collectively oblique to one another. In the mature meninx cells are scanty. The included blood vessels lie mainly along the junction of the two layers; elsewhere they are more frequent in the inner than in the outer layer. Elastic fibres are both delicate and scanty. Bounding the subdural space is an inner areolar layer, so thin as to be practically linear in vertical sections. This contains a few 
capillaries and is limited by a flattened endothelium of polygonal cells (Weed, '1932), which, however, is not obvious in sections of human necropsy material.

\section{Purulent Pachymeningitis}

Early Stages.-Purulent pachymeningitis is a misnomer in that the dura remains remarkably free from infiltration by the leucocytes that collect in the subdural space, with the exception of areas contiguous to bone affected by purulent osteomyelitis. But its reactions, and those of the opposing leptomeninges, are characteristic and resemble those seen in subdural hæmatoma. They are, however, of a more vigorous character and determine the organization and segregation of the adjacent pus.

At an early stage proliferation of blood vessels and multiplication of large mononuclear macrophages begin in the inner layer of collagenous fibres, and in the boundary zone between this and the outer collagen layer. There is little alteration of the latter. The proliferating vessels and cells extend inwards to enter the fibrin and pus in the subdural space. First the large mononuclear cells are seen in small groups, in active phagocytosis, immediately beneath the dura. Later they are followed by capillaries. Fibroblasts then appear also, and lay down collagen fibres. By a progression of this sequence of changes from without inwards a layer of fibrous granulation tissue comes into being which is incorporated with the inner areolar layer of the dura and gradually encroaches on the pus.

Simultaneous changes occur in the leptomeninges. Provided that the infection does not extend into the subarachnoid spaces the inflammatory changes found in the latter are non-purulent. At the earliest stages the leptomeninges are distended by œdematous exudate containing abundant filaments of fibrin. Polymorphonuclear leucocytes are scanty, and are exceeded in number by large mononuclear cells (phagocytes) of arachnoid origin. These quickly multiply and become the predominant cell. The pia at first is little affected, but later there is a chronic type of inflammatory cellular infiltration characterized by plasma cells, lymphocytes, and large mononuclear cells.

As in subdural hæmatoma, so here too the leptomeninges provide a granulation tissue that organizes the subdural exudate from below. The reaction is slower and less vigorous than that which takes place from the dural side. Large mononuclear cells, however, migrate through the arachnoid membrane to invade the pus, and are followed later by capillaries and spindle fibroblasts, which lay down rather scanty collagen fibres.
Later stages are those of complete organization and gradual regression to a resting stage. Provided that complicating pathological conditions do not arise, the pus in the subdural space will ultimately be replaced by macrophages : the advancing ranks of célls from dura and arachnoid respectively meet and form a united layer. At this stage the dura and arachnoid are in close apposition, lightly adherent by a moderately firm opaque yellow film, which at first may be easily broken down manually but which soon becomes organized by collagen so that the brain is firmly united to the dura (Plate II a).

But this presupposes that the exudate amounts to no more than a thin layer. In places the accumulation of pus may be relatively great, and here it is found that organization is completed about the margins, where the pus is scantier, while the central collection forms an abscess. Certain of the localized subdural abscesses that occur in the course of a more diffuse infection of the subdural space are therefore simply areas where organization is delayed by the greater bulk of the exudate.

Where the exudate is minimal it may be completely removed with no greater residua than slight fibrous thickening of the innermost areolar layer of the dura, with perhaps a little perivascular lymphocytic infiltration.

With the development of organized tissue in the subdural space the dura reverts to its normal content of cells and blood vessels. The leptomeninges, on the other hand, undergo fibrous thickening and the chronic inflammatory cellular exudate in the pia persists for considerably longer periods.

Resolution after Treatment by Penicillin.-In one case in the present series it is possible to report the histological appearances, following successful treatment of suppurative pachymeningitis by irrigation of the subdural space with a penicillin solution. This patient died of a loculated right subdural abscess, and on the left side where the original purulent pachymeningitis had been encountered there was at necropsy no macroscopic abnormality other than diffuse orange staining of the inner aspect of the dura, and a few delicate adhesions between arachnoid and dura.

Microscopically the dura of this region showed the slight fibrous thickening of the inner areolar layer already described as the end result of complete resolution. A few pigment-macrophages, plasma cells, and lymphocytes were present in this layer. The leptomeninges had undergone slight fibrous thickening, both of arachnoid and pia, and contained a slight excess of perivascular lymphocytes and large mononuclear cells. A few arteries over the 
convexities of convolutions showed endarteritis fibrosa. In the subjacent cortex of some areas there was diffuse atrophy of the superficial layers, with an increase of microglial cells and of blood vessels, mainly capillaries. The appearances as a whole, therefore, were indicative of healing, with slight residual chronic changes in the meninges and focal low-grade ischæmic alterations in the cortex.

\section{Associated Lesions}

Spreading Osteomyelitis of the Skull.-The commonest associated lesion (Table III) is spreading osteomyelitis of the skull, and most often this is secondary to chronic infection of the accessory nasal sinuses (nineteen cases). An acute exacerbation of the sinus infection, or some surgical procedure such as a nasal or external operation on the paranasal sinuses, or tooth extraction, has often appeared to precipitate the onset of pachymeningitis. Osteomyelitis was found more commonly at clinical examination and at operation than at necropsy. In some cases it appeared to be of rapid development, and was quickly followed by pachymeningitis ; in others it was a more chronic process lasting for weeks or even months. (Plate IVa).

In the acute form there was œdema and venous engorgement of the scalp; at operation the pericranium stripped easily and the exposed bone oozed blood from many points. Sometimes there was an extradural abscess. In the diploe beads of pus were often seen. In the acute stage radiographs often showed no abnormality; but later, in the cases which recovered, areas of osteomyelitis could be identified as irregular lines of diminished density enclosing areas of normal looking bone (Fig. 4), and sometimes a layer of new bone could be seen between the inner table of the skull and the dura. In patients treated with penicillin there was sometimes no abscess or sequestrum-formation from these areas, and the only evidence of spreading osteomyelitis was radiographic; in other cases subpericranial abscesses formed and pus and a few spicules of bone discharged from various points in the skull. At necropsy, near the site of primary infection in the paranasal sinuses or mastoid, sequestra of various sizes were found ; and in one case, in which infection had spread from the maxillary antrum, there were chronic abscesses embedded in dense fibrous tissue in the pterygoid muscles and these were in contact with the inferior surface of the adjacent greater wing of the sphenoid.

When the osteomyelitis was mainly unilateral the subdural suppuration occasionally involved the contralateral cerebral compartment.

Extradural Abscess.-Extradural abscess, a sequel of osteomyelitis, may precede or accompany pachymeningitis and in the latter case may even be at a distance from the primary source of the infection (Case 2).

Thrombosis and Thrombophlebitis.-Thrombosis of the large dural sinuses, especially the superior longitudinal sinus, and retrograde purulent thrombophlebitis extending into the superficial cerebral veins was less common in our series than in that of Kubik and Adams (1943). When it occurs purulent leptomeningitis is superimposed upon the nonpurulent subarachnoid inflammation which has already been described, at any rate in the region of the affected veins and sinuses. As a further sequel to venous thrombosis there are profound circulatory disturbances in the aqdjacent brain : severe degeneration of the neurones is accompanied by gross œdema, proceeding to venous infarction and hæmorrhages. Spread of infection by the perforating veins may result in suppuration in already softened areas. The patient usually succumbs before a well-defined cerebral abscess is formed ; but clinically, since the introduction of penicillin, we have encauntered one or more large abscesses in the brain some weeks after the onset of pachymeningitis (Plate III).

Thrombosis may occur in one or more superficial cerebral veins without sinus-thrombosis and without infection of the leptomeninges. As a sequel, severe circulatory disturbances may occur in the subjacent cortex, with œdema and patchy neuronal degeneration which may go on to necrosis.

When purulent leptomeningitis complicates pachymeningitis, venous thrombosis is again a frequent sequel. Diffuse superficial encephalitis accompanies the more severe infections, with some polymorphonuclear infiltration in the early stages and, later, infiltration with mononuclear macrophages and proliferation of small blood vessels where destruction of cortical tissue has occurred.

Ventriculitis.-Ventriculitis was uncommon unless much surgical intervention, such as multiple needlings for abscess, had assisted the passage of infection.

Thrombosis of the Carotid Arteries.-Thrombosis of the carotid arteries in the neck was probably present in one of our cases (Case 4).

Lung Involvement.-Lung abscess and purulent bronchopneumonia were seen, and in this connexion it must be noted that Williams (1944) has described a group of cases of pansinusitis accompanied by bronchiectasis. Some of our cases of purulent pachymeningitis may have had suppurative lung lesions before they ever got subdural infection. 
Septicæmia.-Septicæmia was observed in some of our cases at necropsy but we did not obtain any positive blood cultures during life, nor have we got unequivocal evidence of its presence in purulent pachymeningitis uncomplicated by osteomyelitis of the skull and other infective lesions known to produce septicæmia.

Purulent pachymeningitis is no exception to the rule that in intracranial infections almost any combination of infective lesions may arise. The valuable histological studies of Turner and Reynolds (1931) have demonstrated the diverse channels by which infection from the paranasal sinuses and mastoid process may spread into the cranium. In the past the infection has often spread so rapidly that it has been impossible to follow the trend of events clinically; and furthermore the risk of spreading the infection by opening the dura or puncturing of the lateral ventricles through an infected field has precluded investigations which might have materially assisted in diagnosis. But now the march of infection is often slowed with antibiotics, and the risk of spreading infection by surgical diagnostic measures such as ventricular puncture becomes greatly reduced. Cases that formerly would have been hopeless can now be cured by antibiotics and operative removal of purulent lesions. Consequently the habits of spreading intracranial infection assume a new importance.

In purulent pachymeningitis the starting point of infection is usually the skull: either the bone around the paranasal sinuses, or the petrous bone, or some other part of the skull infected by metastatic spread from a distant source. The sequence, usually, is osteomyelitis, extradural abscess, purulent pachymeningitis, also sometimes sinus thrombosis or thrombophlebitis of the cerebral veins; and terminally leptomeningitis. Extension to the brain itself is rarely of any magnitude in the cases not treated with antibiotics, for they are too soon fatal ; but cerebral abscess may develop in the cases subjected to penicillin.

Less commonly there is simultaneous lepto- and pachymeningitis ; or leptomeningitis may even precede pachymeningitis, as in one of our pneumococcal cases.

Thus, even without any consideration of spreading intracranial infection which does not involve the subdural space, there is an almost bewildering array of clinical possibilities, and the clínical picture is important in indicating the trend of events. This is one of the reasons why all those who are interested in intracranial infections should become familiar with the syndrome of purulent pachymeningitis.

\section{The Clinical Picture}

With early penicillin treatment the full clinical syndrome may not be seen. For recognition of the partial forms it is necessary to understand the complete form, and this will now be described. The clinical picture is distinctive (Cairns, 1930 ; Kubik and Adams, 1943). For a few hours the patient, who is usually in hospital for accessory nasal sinus or mastoid disease, may be restless and unlike himself, feverish, and perhaps complaining of headache. Then an arm or leg becomes weak, the eyes show persistent deviation away from the side of the paralysed limb and weakness of conjugate deviation to the opposite side, and within twentyfour hours the patient has a complete ffaccid hemiplegia. The hemiplegia is frequently preceded by focal motor fits. If the dominant hemisphere is involved difficulty of expression may be the first symptom and the patient soon becomes grossly aphasic.

As the infection spreads in the subdural space it is often possible to demonstrate a complete homonymous hemianopia, and, if speech and consciousness are retained, severe sensory loss in the paralysed limbs (Case 1). More usually the patient is aphasic or drowsy and all that can be discerned is an absence of response to menace from the appropriate side and delayed appreciation of painful stimuli of the affected limbs. In short, the signs are those of a cortical paralysis of one cerebral hemisphere.

When the condition arises from mastoid infection or spreads from the maxilla to the middle cranial fossa the subdural pus may first spread over the base of the brain, and the prominent initial symptom then may be drowsiness. But even in these cases hemiplegia and homonymous hemianopia ensue with considerable frequency, even though the subdural pus is mainly on the inferior and medial surfaces of the hemisphere instead of mainly on the convexity, as it is when the infection arises from the frontal sinuses.

Intracranial pressure rises and papillodema of mild or moderate degree may develop. There is often some stiffness of the neck, and the clinical observer may thus be surprised to find that the lumbar cerebrospinal fluid contains no more than 100 to 300 white cells per c.mm. and no organisms. In these circumstances it may be tempting to make a diagnosis of cerebral thrombophlebitis. The clinical pictures of the two conditions may resemble one another closely, and differential diagnosis is complicated by the fact that purulent pachymeningitis is often, though by no means invariably, accompanied by thrombosis of the cerebral venous sinuses and veins. But there are certain distinguishing features. 
Firstly, there is the history of chronic pansinusitis ; in our experience uncomplicated cerebral thrombophlebitis is uncommon in such cases. Secondly, there are the signs of osteomyelitis preceding or accompanying the neurological illness- - edema and venous engorgement of the scalp, temple, or face over the affected bones - high fever $\left(102^{\circ}\right.$ to $105^{\circ} \mathrm{F}$.), and sometimes rigors; with osteomyelitis of the facial bones there may be also trismus and severe facial pain.

\section{Purulent Pachymeningitis before the Discovery of Penicillin}

Case 1. Pansinusitis. Bilateral antrostomy and drainage of frontal sinuses. Spreading osteomyelitis of face and skull. Purulent pachymeningitis (Strep. viridans). Death. (No. 2788, 1936, a patient of Mr. F. C. Capps.)

A male, aged 47, with chronic pansinusitis, developed an infected mucocele of the frontal sinus with a lump on the forehead. Pressure on the lump produced a discharge of pus from the right nostril. Three months later both antra were drained of foul pus by the nasal route (hæmolytic streptococcus and in small numbers Staphylococcus aureus), and drainage of the frontal sinuses was established by removal of the anterior ends of the middle turbinate bones and external resection of the inner part of the floor of the right frontal sinus. For nine days the patient did well, and then he developed a spreading osteomyelitis of the facial bones with fever, swelling, and abscess formation about the eyes and upper jaw, for which further operations were required. His wounds discharged much pus and he became weak, wasted, and anæmic.

He was given sensitized streptococcal vaccine, prontosil, and blood transfusions, but the facial osteomyelitis continued and, twelve weeks after its onset, spread to the frontal bone. During the next five weeks the osteomyelitis gradually extended backwards (Plate IV a) and the patient had headaches, facial pain, and slight fever, and became much more irritable.

Purulent pachymeningitis first showed itself on Feb. 4, 1937, about sixteen weeks after the onset of facial osteomyelitis. The patient noticed a weakness and numbness of the right leg, and twelve hours later slight numbness and difficulty of control of the right hand; he vomited twice, and had slight headache and fever $\left(100 \cdot 4^{\circ}\right.$ F.). On examination there was moderate weakness and hypotonia of the right limbs, the leg being worse than the arm. The tendon jerks of the right limbs were increased, the right abdominal reflexes were absent; both plantar reflexes were flexor. In the right big toe passive movements were not appreciated, and in the right thumb the threshold of appreciation of the direction of passive movements was raised. Cotton wool was felt normally on the right upper limb and trunk, but on the right lower limb was felt only on strong stimulus and as a cold, tickling sensation. Pin point was felt on the right foot as a cold sensation, on the right leg and thigh as a spreading tingling sensation, on the trunk and upper arm normally as a pin, on the right forearm as a tingling sensation, and on the right hand as a blunt pin.
About eighteen hours after the onset of sensori-motor signs the patient began to show slight dysphasia and an attention defect in the right homonymous fields. On the next day, Feb. 5, he had gross defect of understanding and of expression. His right lower limb was completely and his right upper limb almost completely paralysed, his left leg at times was clumsy and weak, and light stroking of each foot produced an unpleasant overreaction. He was incontinent of urine and fæces, and his neck was slightly stiff.

Operation in the left parietal region (Feb. 5) showed gross osteomyelitis with subpericranial pus and granulations on the outer surface of the dura. When the dura was opened thick pus was found free in the subdural space, and small amounts could be collected for some time by depressing the brain away from the dura. The left parietal lobe was needled, but no abscess was found. Films of the pus showed pus cells and streptococci, and cultures yielded Streptococcus viridans.

The patient grew steadily worse and died on Feb. 9.

As there was no necropsy we cannot exclude the possibility that there was also a thrombosis of the sagittal sinus and cerebral veins; our necropsy studies on other cases suggest that such lesions usually do not alter the clinical picture in the acute stage.

Because of the relatively late development of aphasia this case shows particularly well the progressive loss of cortical function-flaccid hemiplegia becoming complete in two days and spreading to involve the opposite leg, widespread and rapid sensory loss with paræsthesiæ and overreaction, aphasia, and homonymous hemianopia. The patient died five days after the onset of neurological symptoms.

In earlier days spreading osteomyelitis of the skull of this type was treated by widespread removal of bone, but with little success. Of twenty cases of diffuse osteomyelitis following operations on the paranasal sinuses all died (McKenzie, 1913). In Case 1 this treatment could not be employed early because the facial bones were so widely affected. Prontosil and vaccines did not materially arrest the spread of the disease.

Purulent pachymeningitis does not always run such a rapid course. Plate II a shows the brain of a man of 42, in whom the illness lasted for thirteen days, during which flaccid left hemiplegia and aphasia (he was a left-handed man) fluctuated in intensity. On some days there would be improvement in tone and return of power in the paralysed limbs, with improvement in understanding and occasionally, but only to a slight degree, of speech. Thus, one day the left upper limb was flaccid and completely paralysed; next day tone was normal, good power was present at all joints, and the ergometer record of the left hand-grip was 
30 as compared with 45 on the right. On some days, when the left upper limb seemed quite flaccid and paralysed, with strong exhortation the patient would suddenly flex it voluntarily at the elbow, through a considerable range. This phenomenon suggests that the paralysis differs from that caused by compression of the pyramidal tract or precentral gyrus by tumour, and that it results from a lesion at a higher level than the precentral gyrus. It is indeed remarkable that a relatively thin film of pus in the subdural space can produce such complete hemiplegia. Blood accumulating in the subdural space at the same rate does not produce the same degree of paralysis, if indeed it produces any. Nor does subarachnoid pus have the same effect; indeed it is uncommon to see complete motor paralysis of a limb in purulent leptomeningitis. Subdural pus spreads more rapidly than subarachnoid pus, and it may be that it is the diffuseness of the cortical involvement which is the essential cause of the cortical paralysis.

Terminal Events. - Without penicillin the majority of our fatal cases (eighteen out of twenty-six) have died within two weeks of the onset of neurological symptoms. Signs of spread of the subdural suppuration to the opposite hemisphere appear in the form of paralysis, with or without motor fits, of the hitherto healthy side. Severe rise of intracranial pressure evidently contributes to death in a considerable proportion of cases, for at necropsy there is often severe herniation of the uncinate gyri through the tentorial opening and of the cerebellar tonsils through the foramen magnum. We have even seen hæmorrhage into one herniated cerebellar tonsil, which is an indication of rapid and severe herniation. Pulmonary complications and in one case renal failure have contributed to death.

Modification of the Clinical Picture in Cases Treated with Penicillin.-With adequate systemic penicillin in the early stages of the illness the clinical picture may be modified. There may be no obvious signs of osteomyelitis of the vault of the skull, hemianopia may be absent or incomplete, and the overt motor and sensory paralysis may be limited to one limb. The condition can still be recognized by the fact that signs of cortical paralysis come on suddenly after gross infection of the paranasal sinuses or petrous bone and without obvious leptomeningitis, but differential diagnosis from cerebral thrombophlebitis may be very difficult without exploration of the subdural space by means of burr-holes. Diagnosis is made more difficult by the fact that with penicillin and inadequate surgery in the early stages purulent pachymeningitis may be complicated by cerebral abscess.
TABLE IV

DISTRIBUTION OF TYPES OF STREPTOCOCCI

\begin{tabular}{l|c||c|c|c||c}
\hline & $\begin{array}{c}\text { Total } \\
\text { Strep. } \\
\text { cases }\end{array}$ & $\begin{array}{c}\text { Detailed } \\
\text { records }\end{array}$ & $\begin{array}{c}\text { Anæ- } \\
\text { robic }\end{array}$ & $\begin{array}{c}\text { Viri- } \\
\text { dans }\end{array}$ & $\begin{array}{c}\beta \text {-hæmo- } \\
\text { lysis }\end{array}$ \\
\hline $\begin{array}{l}\text { Sinus } \\
\text { infection }\end{array}$ & 18 & 13 & 8 & 4 & $1 *$ \\
\hline $\begin{array}{l}\text { Mastoid } \\
\text { infection }\end{array}$ & 3 & 1 & 1 & 0 & - \\
\hline $\begin{array}{l}\text { Distant } \\
\text { causes }\end{array}$ & 3 & 3 & 1 & 2 & - \\
\hline Total & 24 & 17 & 10 & 6 & $1 *$ \\
\hline
\end{tabular}

* In addition 1 patient with anærobic streptococcal infection showed also at subsequent drainage of a subdural loculus $\beta$-bæmolytic streptococcus (Case 3).

\section{Bacteriology}

The predominant causal organisms in our series were streptococci of anærobic, or viridans, or non-hæmolytic forms (Tables I and IV). Staphylococcus and $\beta$-hæmolytic streptococcus were rare, although the pus from the paranasal sinuses of our cases usually contained a combination of these two organisms. This is a remarkable finding when we consider that osteomyelitis of the skull is as often $\mathrm{\Phi}$ caused by Staphylococcus aureus as by non- $\beta$ \% hæmolytic streptococci. Comparing our cases of $\varnothing$ osteomyelitis of the skull with and without purulento pachymeningitis (Table V) it is seen that when there is no subdural infection staphylococcus is the? preponderant organism, whereas when there is subdural infection streptococcus, almost invariably non- $\beta$-hæmolytic, is significantly preponderant. The staphylococcal infections tend to become localized, and though they may produce brain abscess they do not cause purulent pachymeningitis ; the streptococcal infections tend to spread along the skull and also through the dura.

The streptococci found in our series were usually

\section{TABLE V}

BACTERIOLOGICAL COMPARISON OF OSTEOMYELITIS OF THE SKULL WITH AND WITHOUT PURULENT PACHYMENINGITIS

\begin{tabular}{l|c|c|c|c|c}
\hline $\begin{array}{c}22 \text { unselected } \\
\text { cases of } \\
\text { osteitis of } \\
\text { skull : }\end{array}$ & Strep. & Staph. & $\begin{array}{c}\text { Strep. } \\
\text { and } \\
\text { Staph. }\end{array}$ & Other & $\begin{array}{c}\text { No } \\
\text { record }\end{array}$ \\
\hline $\begin{array}{l}\text { With purulent } \\
\text { pachymeningitis }\end{array}$ & 19 & 1 & 1 & - & 1 \\
\hline $\begin{array}{l}\text { Without } \\
\text { purulent } \\
\text { pachymeningitis }\end{array}$ & 5 & 14 & 1 & - & 2 \\
\hline
\end{tabular}


in short chains though occasionally in very long chains and sometimes pleomorphic. They often proved difficult to grow and were usually anærobic or microærophilic. Sometimes they showed unusual pigmentation reactions. Now that these patients are apt to be treated with systemic penicillin for a few days before the specimen of subdural pus is obtained by operation the difficulties of cultivation may be greater, requiring the routine use of penicillinase with cultures.

Similar types of streptococci have been observed in spreading osteomyelitis of the skull by Williams and Heilman (1937) and Williams (1944). The same groups of streptococci are also probably today the most common cause of brain abscess uncomplicated by spreading osteomyelitis of the skull or purulent pachymeningitis ; also organisms of the viridans group produce meningitis after cranial operations. And it is interesting to recall that in the final stages of the 1939-45 war, when penicillin was freely available, the non- $\beta$-hæmolytic streptococci were the most serious menace in brain wounds (Cairns and others, 1947). Their identification and classification are as yet far from complete (see Sandusky and others, 1942, and Sherman, 1937, for recent reviews), but evidently are of increasing importance in human disease now that, as a result of penicillin, infections with Staphylococcus aureus and $\beta$-hæmolytic streptococcus are diminishing in frequency and severity.

We had one case of purulent pachymeningitis due to pneumococcus, type VII, and in this case the route of infection appeared to be different ; after acute frontal sinusitis and extradural abscess the patient developed purulent leptomeningitis and within about two days signs of purulent pachymeningitis. There was no evidence of spreading osteomyelitis of the skull (Cairns and Russell, 1946, Case 5).

Penicillin Sensitivity of Non- $\beta$-hæmolytic Streptococci.-The cases which we have been able to treat adequately with penicillin have shown good clinical response to treatment. The sensitivity of the organisms to penicillin in vitro was recorded in only four cases. In two, one an anærobic streptococcus, the other an $\alpha$-hæmolytic organism of the viridans group (Case 2) the organism was completely inhibited by 0.04 units per c.cm. of penicillin, while in a third a non-hæmolytic streptococcus was completely inhibited by 0.01 units per c.cm. In the fourth Dr. E. S. Duthie found that the organism, a short-chained streptococcus which grew without hæmolysis under ærobic and anærobic conditions, was completely insensitive on blood plates to penicillin at the usual dilutions. There was some inhibition by 20 units per c.cm. but none by 5 units per c.cm. This organism was also insensitive to sulphathiazole, sulphapyridine, and sulphadiazine. The patient showed no response to limited chemotherapy, which, owing to shortage of supplies, did not include systemic penicillin.

\section{Theory of Treatment}

With very few exceptions the organisms producing purulent pachymeningitis are sensitive to penicillin, even the anærobic streptococci (Hempstead, 1944), though some of these may be relatively resistant and require much larger doses than are adequate against Staph. aureus and $\beta$-hæmolytic streptococcus. In most cases of purulent pachymeningitis infecting organisms are present not only in the subdural space, but also in the skull and facial bones, and probably on occasions in the leptomeninges. In some cases there may also be macroscopic collections of pus in the extradural space and in the brain substance as well as in the subdural space, and there may be infected clot in the sagittal sinus and cerebral veins. To combat these areas of infection it is necessary to give penicillin by three routes, and macroscopic collections of pus must be removed by operation since they usually cannot be sterilized by penicillin.

\section{Penicillin}

Subdural Injection.-Systemic penicillin passes freely into the subdural space (Table II) and it is possible that an adequate amount might be supplied there by very large and frequent intramuscular doses. Our limited experience suggests, however, that it would be unwise to rely exclusively on the systemic route (Case 6). Subdural injections can produce a higher concentration in the subdural space, and moreover the mechanical effect of the injected solution must aid in providing access of the drug to the organisms and also in preventing loculation of the pus. Furthermore, since penicillin passes rapidly from the subdural space into the blood stream (Smith, Duthie, and Cairns, 1946, Case 8) by way of the dural veins, which have free communication with the diploic veins of the overlying skull, it is probable that high values of penicillin are obtained in the infected coverings of the subdural space. Elder (quoted by Robertson, 1900) found that coloured injections into the subdural space of a recently killed animal very quickly passed through the dura into the veins both of this membrane and of the skull.

The penicillin is instilled directly into the space, through an in-dwelling catheter, at intervals of three to four hours, since it is rapidly absorbed by the blood stream.

Systemic Injections.-Systemic penicillin passes 
into fluids in the subdural space (Smith and others, 1946 ; Cairns, 1947). It is also required to combat the infecting organisms in the skull or elsewhere. As these organisms may be relatively resistant to penicillin, large doses should always be employed systemically - not less than 100,000 units every three hours until the sensitivity of the organism in vitro has been tested. Experience shows that the skull infections may persist for a long time, even under treatment, and relapse may follow promptly if penicillin is withdrawn too soon (Case 2). Therefore systemic injections should be continued for at least eight weeks.

Subarachnoid or Ventricular Injection.-Subarachnoid injections are of no use for the pachymeningitis, but may be required for the associated leptomeningitis. It is now definitely established that only traces of penicillin pass from the blood to the cerebrospinal fluid and that patients with meningitis, for example pneumococcal meningitis, can relapse while undergoing full systemic treatment only ; also that penicillin injected into the subdural space does not reach the subarachnoid space (Case 2; also Smith and others, 1946, Case 8). Although in the early stages leptomeningitis is usually slight, it is probably wise to give lumbar or ventricular injections of penicillin $(10,000$ to 15,000 units per c.cm.) once daily in the first days of treatment, or longer if the cerebrospinal fluid contains organisms or many pus cells. Sulphadiazine by mouth, with due precautions against renal block, is also very useful for a continuing mild leptomeningitis.

The surgical procedures necessary in the treatment of purulent pachymeningitis frequently entail risk of contamination of the cerebrospinal pathways : for example when a brain needle seeking for a subdural loculus enters the lateral ventricle. In such circumstances a prophylactic dose of penicillin should be injected into the ventricle.

Operative Treatment.-In purulent pachymeningitis exploration of the subdural space does not usually yield a large amount of pus, and the surface of the brain quickly plugs the drainage hole in the dura. The most satisfactory method is instillation of penicillin solution through one or more catheters (Plate IV b) ; this tends to wash out the pus, to spread penicillin to all parts of the subdural space, and, if done sufficiently early and often, to prevent the development of loculated subdural abscess.

Wide surgical removal of the infected skull and facial bones in the acute stage can no longer be considered necessary, for under penicillin treatment most of the osteomyelitis will subside without obvious sequestration. But usually there will be one or more areas in which osteomyelitis goes on to necrosis, sequestration, local subaponeurotic abscess, and sinus formation. Though even this may subside satisfactorily under continued systemic penicillin, assisted by the spontaneous discharge of pus and bone spicules (Case 2), it is wiser to remove the residual necrotic or suppurative foci of osteomyelitis in the subacute or chronic stage in order to diminish the risk of subsequent relapse of cranial or intracranial infection. In facial osteomyelitis it may be impossible to remove all the infected bone ; in such cases it would probably be necessary-we have not had personal experience on this point-to continue systemic penicillin uninterruptedly for months.

It has now been fully established that penicillin cannot gain access to any large collection of pus in sufficient amounts to sterilize it, and therefore an essential part of the treatment is evacuation of such collections. The surgeon must therefore be ever on the alert to detect localized collections of pus in the subdural space or elsewhere, and on the apparently healthy side as well as on the side which is obviously involved. The associated pyogenic lesions include extradural abscess, brain abscess, and suppurative thrombosis of sagittal or lateral sinuses. Loculated subdural abscess is the most common sequel of the spreading purulent pachymeningitis, especially on the medial and inferior surfaces of the cerebral hemisphere.

\section{Experience since the Introduction of Penicillin}

All our patients treated before the discovery of penicillin died (Table VI). Also all patients died who, owing to shortage of supplies in the early days of penicillin, could not be given the drug systemically and were treated only by the subdural route; however in some of these the clinical picture was modified. Largely as a result of attenuation of the infection by penicillin we recognize three clinicopathological groups of cases according to the behaviour of the intracranial suppuration under treatment : (1) uncomplicated purulent pachymeningitis (5 cases); (2) purulent pachymeningitis

TABLE VI

RESULTS OF TREATMENT

\begin{tabular}{|c|c|c|c|c|}
\hline $\begin{array}{c}\text { Dose } \\
\text { of } \\
\text { penicillin }\end{array}$ & Died & Recovered & Total & $\begin{array}{c}\text { Loculated } \\
\text { subdural } \\
\text { abscess }\end{array}$ \\
\hline $\begin{array}{l}\text { None } \\
\text { Inadequate } \\
\text { Adequate .. }\end{array}$ & $\begin{array}{r}18 \\
5 \\
3\end{array}$ & $\begin{array}{c}\text { None } \\
\text { None } \\
7\end{array}$ & $\left.\begin{array}{c}5 \\
10\end{array}\right\} 15$ & $\left.\begin{array}{l}3 \\
6\end{array}\right\}^{7} 9 *$ \\
\hline Total $\ldots$ & 26 & 7 & 33 & 16 \\
\hline
\end{tabular}

* Combined in 3 cases with cerebral abscess. 
TABLE VII

CLASSIFICATION OF CASES TREATED WITH PENICILLIN

\begin{tabular}{|c|c|c|c|c|}
\hline \multirow{3}{*}{$\begin{array}{l}\text { Clinico-pathological } \\
\text { group }\end{array}$} & \multicolumn{4}{|c|}{ Penicillin } \\
\hline & \multicolumn{2}{|c|}{ Adequate } & \multicolumn{2}{|c|}{ Inadequate } \\
\hline & $\begin{array}{l}\text { No. } \\
\text { of } \\
\text { cases }\end{array}$ & Died & $\begin{array}{l}\text { No. } \\
\text { of } \\
\text { cases }\end{array}$ & Died \\
\hline $\begin{array}{l}\text { Uncomplicated purulent } \\
\text { pachymeningitis.. }\end{array}$ & 3 & - & 2 & 2 \\
\hline $\begin{array}{l}\text { Pachymeningitis followed } \\
\text { by loculated subdural } \\
\text { abscess . . . . }\end{array}$ & 5 & 2 & 1 & 1 \\
\hline $\begin{array}{l}\text { Pachymeningitis plus sub- } \\
\text { dural abscess plus cere- } \\
\text { bral abscess }\end{array}$ & 2 & 1 & 2 & 2 \\
\hline Totals & 10 & 3 & 5 & 5 \\
\hline
\end{tabular}

followed by loculated subdural abscess ( 6 cases) ; (3) purulent pachymeningitis followed by loculated subdural abscess which in turn is followed by cerebral abscess ( 4 cases) (Table VII).

Uncomplicated Cases.-The following is an uncomplicated case which illustrates the therapeutic methods and the stages of recovery; and it was probably the first case of purulent pachymeningitis to be treated successfully with penicillin, which Sir Howard Florey kindly provided from his meagre stocks early in 1943.

Case 2. Pansinusitis. Bronchopneumonia and empyema. Acute osteomyelitis of skull and purulent pachymeningitis (Strep. viridans). Evacuation of subdural pus. Penicillin by subdural and systemic routes. Recovery. (No. 5912.)

A private, aged 28, on enlistment in the Army in 1940 was found to have severe dental sepsis, but he had never been ill until April 9, 1943, when he developed pain and swelling of the left eye, with fever up to $103^{\circ} \mathrm{F}$. These symptoms continued, and were accompanied by cough and pain in the left side of the back and neck. On April 16 he was admitted to a military hospital with a temperature of $102 \cdot 6^{\circ} \mathrm{F}$., a pulse rate of 100 , and respirations 20 per minute ; he had a purulent bloodstained discharge from the left nostril, and was acutely tender over the occipital muscles on the left side. Radiographs showed opacity of both maxillary antra and of the left ethmoid sinus, and slight haziness of both frontal sinuses. On April 18 he developed bronchopneumonia at both bases, with a pleural rub on the left side. He was given full doses of sulphathiazole for five days without improvement.

On April 22 both maxillary antra were punctured and irrigated. The bone was unusually soft. Thick, green pus was obtained from each side, and from the left side a large slough. On the following morning he was worse: previously co-operative and courteous, he was now surly and taciturn; in the afternoon he became confused and restless, and did not recognize his wife. On the morning of April 24 he developed aphasia and right brachial monoplegia, and during the day he became increasingly drowsy. He was transferred to the Military Hospital for Head Injuries, Oxford.

On admission his temperature was $102 \cdot 4^{\circ} \mathrm{F}$., the pulse rate 108 , and respirations 40 per minute. $\mathrm{He}$ was slightly cyanosed and drowsy, but easily roused. He understood only simple commands, and was completely mute, with slight dysphagia, moderate neck rigidity, gross engorgement of arteries and veins of the scalp, with slight generalizedœdema and engorgement of retinal veins. There was no response to menace in the right homonymous visual fields, and slight bilateral proptosis, more marked on the left side. There was slight weakness of the right side of the face, complete flaccid paralysis of the right upper limb, moderate weakness of the right lower limb, absence of right triceps and supinator jerks, and diminution of right biceps and knee jerks; but the right ankle jerk was normal. Abdominal reflexes were absent on the right side and greatly diminished on left ; the plantar reflexes were normal. He had delayed appreciation of pin-prick on the right side. Signs of consolidation at the bases of both lungs were more marked on the left side. Lumbar puncture showed an initial pressure of $300 \mathrm{~mm}$. , a total protein of $80 \mathrm{mg}$. per $100 \mathrm{c.cm}$., white cells 44 per c.mm. (mainly polymorphs); cultures were sterile. Blood culture was sterile, and blood sedimentation rate $53 \mathrm{~mm}$. in the first hour. There was slight secondary anæmia (white blood cells 14,200 per c.mm.).

Operation : April 24.-Through a right parietal burrhole the bone looked normal. There was a small amount of clear fluid in the subdural space, and the arachnoid looked normal and was flush against the dura. Through a left frontal burr-hole thin pus escaped from the diploe. The left subdural space contained thick pus which escaped whenever the brain was displaced away from the dura ; $5 \mathrm{c.cm}$. were collected. A rubber catheter was passed through the burr-hole to the posterior end of the subdural space (Plate IVb) and $5 \mathrm{c.cm}$. of calcium penicillin solution (1,250 units) were injected through it. The scalp was unusually vascular, and much more blood was lost than is usual in such a small operation. Blood transfusion (1 pint) was given.

Bacteriology.-Films of the diploic and subdural pus showed Gram-positive cocci in clumps and chains. On culture this organism proved to be $\alpha$-hæmolytic and was provisionally classified as Streptococcus viridans. It was completely inhibited by penicillin 0.04 units per c.cm., but gave normal growth in serum broth containing $10 \mathrm{mg}$. of sulphapyridine per cent. (Drs. B. Moore and Margaret Jennings).

Penicillin Treatment.-By the intramuscular route 120,000 units were given daily between April 24 and May 11 (1,820,000 units), and 90,000 units daily between May 16 and May $24(706,000$ units). Into the left 
subdural space between April 24 and May 20 153,000 units were administered $(5 \mathrm{c} . \mathrm{cm}$. of a 250 units per c.cm. solution, three-hourly until May 7 and thereafter less frequently). Intrathecally (at the conclusion of the lumbar punctures between April 24 and May 9) 10,000 units were given.

In addition blood transfusions were given on several occasions, and for the first four days after operation an intravenous saline drip. For the first two weeks, owing to dysphagia, feeding was by nasal tube.

Progress.-On April 26 (two days after initiation of treatment) the general condition was improving. The patient was more alert and fairly strong, and voluntary power suddenly returned to the proximal joints of the right upper limb. The right plantar reflex was now extensor. There was delayed appreciation of pin prick on the right side, as before. There was less engorgement of the scalp vessels, but the scalp was still œdematous. There was slight bilateral papillœdema with one retinal hæmorrhage. In the afternoon he had a generalized convulsion, involving the right limbs more than the left, followed by a state of spasticity with increased tendon jerks of the right limbs.

By April 29 there had been no further improvement in the power of the right limbs. He was still speechless and more drowsy. Dullness at the base of the left lung had increased. The left chest was explored by needle, and $5 \mathrm{c.cm}$. of thin pus, containing in films and cultures a streptococcus identical with that obtained from the subdural space, was aspirated.

On April $\mathbf{3 0}$ he was drowsy and at times restless. Pus discharging from the left frontal burr-hole showed poorly-stained streptococci. Owing to the lack of improvement it was feared that pus might be pocketing in the posterior part of the subdural space. A left parietal burr-hole was accordingly made. The surface of the brain looked healthy; when it was pressed away from the dura $10 \mathrm{c.cm}$. of subdural pus were obtained, similar in character to that from the left frontal region and yielding a very slight growth of streptococcus. A right frontal burr-hole was also made and from the diploe came pus which showed in films Gram-positive cocci, mostly intracellular, and sterile in culture. There was a thin layer of new bone on the inner table of the right frontal region. When the dura was opened about $1 \mathrm{c.cm}$. of thin fluid was obtained, and the brain looked healthy.

On May 2 there was increase of papillœdema, still some engorgement of the scalp vessels and gross œedema over the posterior part of the vertex. Radiographs showed a circular area ( 4 by $4 \mathrm{~cm}$.) of osteomyelitis in the mid-frontal region (Plate $\mathrm{V}$ a), scattered areas of rarefaction alongside the posterior part of the sagittal suture, changes in the bony outlines of the frontal sinuses, and gross opacity of both maxillary antra and of the left ethmoidal sinuses.

On May 7 speech returned, monosyllabic and slurred. Comprehension was still impaired. The scalp was no longer engorged, and œedema was less. By May 9 sensation of the limbs was normal. Chest signs had disappeared. Radiographs showed no spread of the osteomyelitis of the frontal bone. Nasal feeding was stopped as he could now swallow well. By May 11 power was improving and he was sitting up in bed, though he still had partial right homonymous hemianopia. He was no longer incontinent of urine. Systemic penicillin was stopped, owing to shortage of supplies.

On May 16 he complained of frontal headache and said he was not so well. There was considerable discharge of pus from the right frontal burr-hole (intracellular cocci, but cultures sterile). The scalp was again engorged. Osteomyelitis had evidently recurred, but without worsening of neurological signs. Systemic penicillin was resumed.

By May 20 speech and understanding, and also power of his right limbs had improved. The left subdural tube was removed and subdural penicillin stopped. On May 24 systemic penicillin was stopped again and a course of sulphanilamide begun. He was gaining weight rapidly. On June 1 extracranial pus aspirated from the region of the right frontal burr-hole contained the infecting organism. Dr. Jennings found that there had been no reduction of its sensitiveness to penicillin.

Subsequent course.-From this time onwards his general condition steadily improved; he was up and about and from July was performing light tasks in the hospital. From time to time pus discharged from the right frontal incision, but this stopped early in July after a course of local penicillin injections through the skin sinus. About this time he had pain in the right side of the chest ; in August he developed a cough and had slight hæmoptysis, and radiographs showed an area of opacity in the middle lobe of the right lung, suggesting consolidation (Plate V c); this had practically disappeared without any signs of cavitation by November, 1943 (Plate V d) at which time he was discharged from the Army.

Soon after leaving hospital early in 1944 he took up work, and he remained in regular employment-though with several changes of job-up to the time when he was last seen in May, 1947. He was a person of little education and poor intelligence, and tests by Major W. R. Reynell during his convalescence had shown a gross defect of abstract thinking and inability to learn new activities. Between January, 1944, and May, 1947, he had eleven sensori-motor epileptic attacks of the right upper limb, in one of which he lost consciousness. On neurological examination in 1947 the only remaining sign was very slight weakness of the right upper limb, sufficient to interfere with his holding money or a cigarette in his right hand but not otherwise disabling. His accessory nasal sinuses and lungs had given no trouble.

In this case, owing to shortage of supplies, the amount of penicillin given systemically was necessarily much less than the optimum dose. In the subdural space large quantities of dilute penicillin solution, a total of $612 \mathrm{c.cm}$. (250 units per c.cm.), were instilled through an in-dwelling catheter at frequent intervals for twenty-seven days. This 
produced no symptoms, unless we are to regard the solitary focal fit on the second day of treatment as due to the penicillin. A little of the solution escaped around or through the catheter immediately after the injections, but very little drained away at other times. The small amounts of penicillin injected into the subarachnoid space, 1,250 units at the conclusion of each lumbar puncture, as a prophylactic measure were probably unnecessary, for there were never more than 43 white cells per c.mm. in the cerebrospinal fluid ; though on one occasion (May 1) a few degenerate cocci were seen in films of the cerebrospinal fluid.

The causal organism, an atypical Streptococcus viridans which was very sensitive to penicillin, disappeared from the subdural fluid some time in the second week of penicillin treatment, but was still present in the pus from the bone eight weeks after penicillin treatment was begun, when it was still as sensitive to penicillin as at the beginning of treatment. Withdrawal of systemic penicillin after eighteen days was promptly followed by recrudescence of osteomyelitis of the skull, with headache and discharge of pus from the right frontal region. In the light of subsequent experience it is remarkable that the diffuse osteomyelitis of the skull was controlled with such small amounts of systemic penicillin given through such a relatively short time (twenty-seven days in all). And it is still more remarkable that the osteomyelitis, which is known to have extended back to the parietal region, healed without any operative removal of necrotic bone (Plate V b). A few spicules of necrosed bone discharged from the right frontal burr-hole; otherwise there was no obvious sequestration.

It was shown in this case and in another (Smith and others, 1946, Case 8) that penicillin in the subdural space does not escape into the cerebrospinal fluid. It is absorbed by the blood stream of the dura mater, which is connected with the overlying skull by very numerous fine vessels, and it is thus possible that during the twenty-seven days of subdural instillations the concentration of penicillin in the skull was considerably higher than would have been obtained with the small doses employed systemically. The fluid injected into the subdural space was freely absorbed : only a small fraction of the $612 \mathrm{c.cm}$. of penicillin solution injected during twenty-seven days escaped from the in-dwelling catheter.

As in Case 1, the symptoms produced by the subdural suppuration were those of a complete cortical paralysis of the left cerebral hemisphere, and the manner in which cortical function recovered is of considerable interest. Recovery from aphasia was slow. Though his understanding was improving, the patient remained mute for two weeks after treatment was begun and dysphasic for a further three weeks. The recovery of speech function was gradual and within a space of fifteen days the following stages were observed : first, monosyllabic answers to questions; then a telegraphic type of utterance and simple sentences with considerable dysarthria; then longer sentences which tailed off unintelligibly at the end ; then requests by name for certain objects; then ability to give a moderately good account of what he read in the newspaper. There was nothing in this recovery of speech which in any way distinguished it from recovery after removal of a benign type of expanding lesion near the speech area.

The recovery of voluntary power, on the other hand, was unlike that of recovery after most cortical lesions. On the first day after penicillin treatment was begun the patient was unable to move his right upper limb though he tried hard to do so, and, . failing, moved it passively with his left hand. Next day, 38 hours after the beginning of treatment, he could move the right upper limb strongly; he maintained it outstretched in mid-air and could voluntarily hyperextend the wrist, though he was still unable to grip. Such remarkably rapid recovery is rarely seen in cortical lesions. The first sign as a rule is feeble movement at the proximal joints, and then there is a gradual increase of power with gradual return of function of the more distal joints. No further recovery was noted for a further two weeks, when at the same time as he started talking he became able to move his right fingers; during the next week movements of the right hand became almost normal, though still for a few days slightly weak, and this weakness became noticeable again for a day six weeks after the onset of treatment. Subsequently, apart from slight clumsiness, his right hand was normal. There was never any increase of tone in his limbs.

Coincidently with the cranial and subdural infection there was a bilateral bronchopneumonia with, on the left side, a small empyema infected with the same organism. The empyema subsided with no more than a single aspiration of $5 \mathrm{c} . \mathrm{cm}$. of pus', and the left lung also cleared up during treatment with systemic penicillin. Infection of the right lung subsequently recrudesced, but after six months and without chemotherapy the radiological signs of consolidation entirely disappeared.

This case and one other early in the penicillin series were the only ones in this series in which pachymeningitis was not complicated by some other intracranial suppuration. Subsequent cases have been complicated by loculated subdural abscess, followed or not by cerebral abscess. 
Purulent Pachymeningitis followed by Loculated Subdural Abscess.-Plate II b shows a loculated subdural abscess. This was in a man who developed intense pneumococcal leptomeningitis after frontal sinusitis and extradural abscess. He was treated by lumbar and systemic penicillin, and when on the tenth day of his meningitis we made parietal burrholes in order to inject penicillin into the ventricles we unexpectedly found free pus in the subdural space on the left side. This was successfully treated by subdural instillations of penicillin through an in-dwelling catheter, and the patient seemed to be progressing favourably until, on the thirty-fifth day of meningeal infection, he developed signs of a right-sided cerebral abscess ; 100 c.cm. of pus was aspirated through a brain needle, and the pyograms -after injection of thorotrast-showed that the pus was not intracerebral but was in the subdural space on the right of the falx. No pus had been seen over the convexity of the right cerebral hemisphere at any of the subdural explorations. This patient died seven weeks after the onset of meningitis. Detailed findings have been reported elsewhere (Cairns and Russell, 1946, Case 5). The post-mortem specimen (Plate II b) shows a collapsed chronic abscess cavity with thick walls, in places crenated in outline, lined on the one side by falx and tentorium, on the other by the medial and inferior surfaces of the right cerebral hemisphere. This is the lesion which has given us so much trouble in our later cases, of which the following is an example.

Case 3. Pansinusitis. Frontal osteomyelitis. Purulent pachymeningitis and leptomeningitis (ancerobic streptococci). Loculated subdural abscess. Penicillin and multiple drainage operations. Recovery. (R.I. 29963, 1944.)

A rather frail boy, aged 11 years, suffered from chronic tonsillitis and adenoids, occasional asthma, and frequent winter colds. In April, 1944, three months before he came under our care, he complained of toothache and a swelling in his right cheek, and there was discharge of pus from the nose. He lost some schooling but was not severely ill until July 3, when he felt tired and took to his bed. On July 6 his right eye became bloodshot, and on the following day a painful swelling appeared on the right side of his forehead. He was admitted to hospital and on July 11 his right maxillary antrum was punctured and washed out. Next day he was found unconscious (probably following an epileptic fit). His neck was stiff and his right limbs did not respond to painful stimuli. On the same night he was transferred to the Radcliffe Infirmary.

On admission on July 12 he was thin, pale, dehydrated, and stuporose, and was unable to produce any articulate sounds. The temperature was $103^{\circ} \mathrm{F}$., the pulse rate 110 , and respiration rate 22 per minute. A fluctuant swelling, about $3 \mathrm{~cm}$. in diameter, projected on the forehead above the right orbit. He had marked neck rigidity. His ocular fundi and pupils were normal. His right limbs were flaccid and paralysed and there was paralysis of conjugate movements of his eyes to the right and slight right lower facial weakness. His left arm was maintained in kataleptic attitudes. The tendon jerks were absent on the right, but present on the left ; his right plantar reflex was extensor and the left flexor in type. Sensory functions and visual fields did not seem to be impaired.

Radiographs showed opacity of the right maxillary antrum and thickening of the walls of the left antrum, impaired translucency of the frontal sinuses, and some destruction of the upper wall of the right frontal sinus. At this time no osteomyelitis was visible radiologically in the cranial vault. Lumbar puncture produced purulent fluid with an initial pressure of $370 \mathrm{~mm}$., cells 7,900 (98 per cent. polymorphs per c.mm.), and protein 250 to $300 \mathrm{mg}$. per $100 \mathrm{c} . \mathrm{cm}$. Films showed pus cells and a few streptococci; cultures were sterile. The white blood cell count was 16,000 per c.cm.

During the following day he had three right-sided focal motor attacks affecting head, eyes, face, right shoulder, and upper limb, in that order, with incontinence of faces. We made a diagnosis of maxillary sinusitis, leading to frontal osteitis, with Pott's puffy tumour, leptomeningitis, and left frontal subdural or possibly intracerebral abscess.

Immediate Treatment.-Penicillin was given by intramuscular drip (120,000 units in twenty-four hours), and into the lumbar theca (8,000 units twice daily) (Fig. 1).

At operation the lateral ventricles were tapped through bi-parietal burr-holes; the cerebrospinal fluid under an initial pressure of $370 \mathrm{~mm}$. was faintly cloudy, and penicillin 8,000 units, was injected into the right ventricle. No subdural pus was found in the parietal areas. Next, bi-frontal, coronal burr-holes were made. On the right side normal tissues were found; on the left 6 to $8 \mathrm{c.cm}$. of greenish-white thick fotid pus were found in the subdural space, and a purulent membrane obscured the view of the underlying cortex. A rubber catheter was tied in the subdural space, through which penicillin $(10,000$ units in $5 \mathrm{c.cm}$. of saline) was instilled, first at three-hourly, then at six-hourly intervals.

On the following day further burr-holes were made to determine the limits of the pus. A mid-frontal burr-hole, slightly to the left of the sagittal sinus just above the orbital roof, revealed subdural pus and another catheter was inserted into the left subdural space for drainage and penicillin instillations. A left anterior parietal and a left subtemporal burr-hole revealed normal conditions, thus showing that, as far as the convex surface of the brain was concerned, the subdural pus was confined to the left frontal area.

A pint of blood was transfused, and he was given phenobarbitone gr. $\frac{1}{2}$ three times a day. He was fed by nasal tube. Four days after admission the Pott's puffy tumour in the right supraorbital region was aspirated ; $0.5 \mathrm{c} . \mathrm{cm}$. of pus was removed and replaced by penicillin solution (2,500 units).

On the day after admission thick pus was obtained at lumbar puncture $(250,000$ cells per c.mm. ; streptococci in films, cultures sterile). This was quite unlike the 
findings at lumbar puncture on previous and subsequent days, when the cerebrospinal fluid contained 7,500 white cells or less per c.mm. There was no evidence of blockage of the cerebrospinal pathways, and it is probable that this pus came from the spinal subdural space. We have seen pus in the spinal subdural space in a case of purulent pachymeningitis following gunshot wound of the brain.

Bacteriology.-The first specimens of lumbar and ventricular cerebrospinal fluid and the pus from the Pott's puffy tumour, showed streptococci but cultures were sterile. The subdural pus showed streptococci on films and streptococci were grown in anærobic cultures. Five days after treatment was begun the organisms had disappeared from the films taken from the cerebrospinal fluid (Fig. 1), and on the seventh day the subdural discharge had ceased. Sulphadiazine was added to the treatment on the eighth day.

Progress.-The focal fits continued in his right lower limb for five days; they were of short duration and inconspicuous. During the first fortnight he gradually became more alert and his right hemiplegia improved slightly. He began to talk in dysarthric monosyllables on the fifth day and later showed perserveration and nominal dysphasia. His neck rigidity became less marked. His temperature became normal during the third week, at which time he was still partly hemiplegic, occasionally incontinent of urine, and still not talking freely.

In the fourth week he began to deteriorate again, nine days after systemic penicillin had been stopped. His intracranial pressure rose (600 mm. plus by lumbar puncture), his temperature rose slightly, his leptomeningitis increased slightly, he developed slight papillœdema and right homonymous hemianopia, and there was increasing weakness of his hemiparetic limbs.

Drainage of Loculated $A b$ scess.-At the end of the fourth week (Aug. 9) the left parietal region was needled, a loculated collection of pus was found in the depths, and air pyograms showed that the pus was in the subdural space on the medial and inferior surfaces of the left hemisphere (Fig. 2). This pus grew a different kind of streptococcus- $\beta$-hæmolytic streptococci-and fusiform bacilli, the latter only for one day. Up to $70 \mathrm{c.cm}$. of pus were aspirated from the cavity and replaced by penicillin, and instillations of penicillin into the abscess were repeated $(6,000$ to 10,000 units once daily).

As the patient remained desperately ill a brain needle was eventually left in this abscess cavity and fixed to the skull by a plaster case for twenty-four hours. Systemic penicillin was resumed. No immediate effect was obtained: the patient remained comatose with moist rales in both lungs and a respiration rate of 70 . After four days he began to respond, and a few days later his intracranial pressure fell to normal.

Nine days after evacuation of the subdural abscess (Aug. 18) his right hemiplegia was still practically complete and his aphasia severe; and he had visual agnosia, attempting to eat a penny in mistake for a biscuit. However, on Aug. 28 his hemiplegia was greatly improved and on Sept. 1 he began to move about in bed and to talk more freely, though still not spontaneously.

In the twelfth week (Oct. 1) he began to get up and about with some help. By then he was physically and mentally free from signs and symptoms, apart from right homonymous hemianopia, generalized debility,
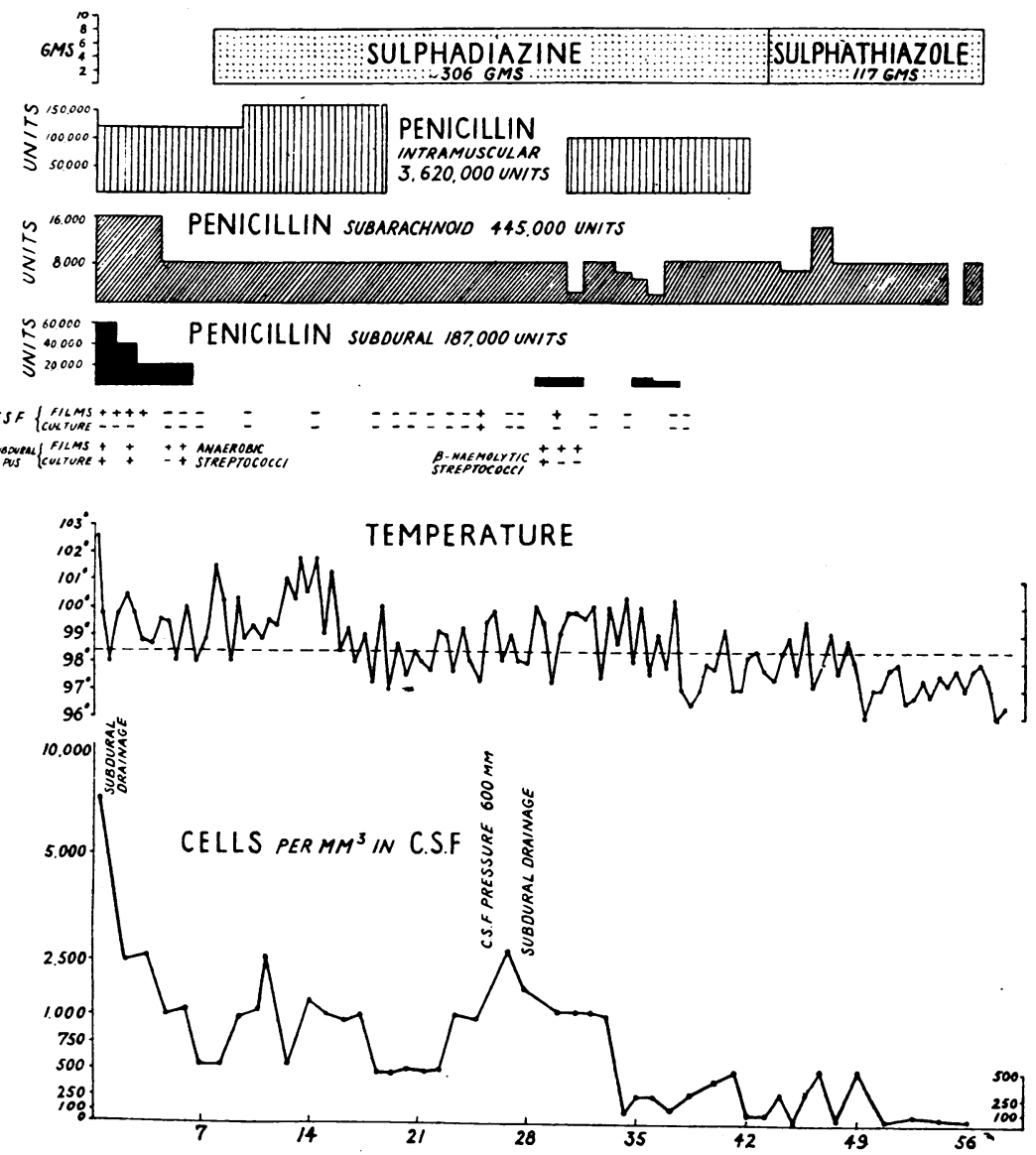

Fig. 1.-Case 3. Chart of illness. 
and severe emaciation. A ventriculogram showed marked ventricular dilatation, slightly more on the left side, with no ventricular displacement (Fig. 3), thus excluding any residual loculation of pus. The cerebrospinal fluid contained $10 \mathrm{mg}$. per cent. of protein and 8 cells. The frontal osteomyelitis (Fig. 4), which had produced the pericranial abscess and had become visible in the later radiographs, subsided without operative removal of the bone. He was discharged from hospital on Oct. 13, 1944, three months after his admission, weighing $3 \mathrm{st}$. $10 \mathrm{lb}$. - a gain of $12 \mathrm{lb}$. in the previous five weeks.

Subsequent Course.-He steadily gained weight. His nose continued to discharge and was found to be obstructed by polyps, and his right antrum remained opaque. Therefore in May, 1945, Mr. G. N. Livingstone performed a right Caldwell-Luc antrostomy and removed the potyps and the anterior parts of the middle turbinate bones. The patient returned to school in September, 1945 and, apart from occasional bouts of rhinitis and a skin rash attributed to taking " Benadryl," he remained well. When last seen in August, 1947, he was making steady progress at school but had not fully caught up with his contemporaries. He had had no fits or headaches. He still had a right homonymous hemianopia which was incomplete in the lower quadrants.

In this case, although the osteomyelitis began on the right side of the frontal bone the purulent pachymeningitis affected the subdural space over the left hemisphere. Leptomeningitis was more severe in the early stage of the illness than in most of our cases and the infecting organism, an anærobic streptococcus, was found in, though not cultured from, the cerebrospinal fluid. The patient was in extremis for several weeks. The left frontal pachymeningitis cleared up with subdural drainage and penicillin, but three weeks later the patient became much worse, and developed papillœedema, right homonymous hemianopia, and severe rise of intracranial pressure, and a large collection of pus was found deep in the left side of the cranium, in the subdural space on the medial and inferior surfaces of the left cerebral hemisphere. After drainage of this abscess and instillation of penicillin the boy gradually recovered ; and subsequently underwent antrostomy and turbinectomy with removal of polyps as a prophylactic against further attacks. Recovery from right hemiplegia was ultimately complete, and from homonymous hemianopia it was partial. The boy is left with dilated ventricles, but his intelligence, though not yet up to former standards, is reasonably good and he has had no fits.

The following case is another example of loculated subdural abscess which differs from the preceding one in having, in addition to osteomyelitis and purulept pachymeningitis, an extradural abscess and also a thrombosis of one common carotid artery.
Case 4. Frontal sinusitis. Spreading osteomyelitis of skull. Extradural frontal abscess. Purulent pachymeningitis (streptococcal). ? Thrombosis of common carotid artery. Penicillin therapy. Loculated subdural abscess and multiple operations. Recovery. (R.I. 40019/45.)

A girl, aged 14 years, with a history of otitis media four years before, developed a cold with copious nasal discharge. Four to five weeks later she came home from work complaining of severe pain in the right supraorbital region. After a week in bed she returned to work for five days, but her pain recurred and she had to take to bed again. Ten weeks after the onset of symptoms she complained of weakness and pins and needles in her left upper and lower limbs, together with intolerable exacerbations of her frontal pain and vomiting, followed by confusion. Two days later she was sent to the Radcliffe Infirmary.

On admission, on March 4, 1945, she was confused but able to answer questions. She had a mild pyrexia $\left(100^{\circ}\right.$ F.) with a pulse rate of 72 per minute, marked meningism, early papillœdema, a complete flaccid left hemiplegia, some sensory loss in the left limbs, and a left homonymous hemianopia. Blood pressure was $110 / 70 \mathrm{~mm}$. Hg. Lumbar puncture yielded a milky cerebrospinal fluid under $300 \mathrm{~mm}$. pressure, containing only 8 cells per c.mm., $120 \mathrm{mg}$. per $100 \mathrm{c.cm}$. of protein, and no organisms either on direct films or culture. Radiographs of her skull showed diffuse mottling of the frontal bone suggesting osteitis, and opacity of the right frontal sinus and right maxillary antrum. The white blood count was 19,000 per c.mm.

Treatment.-Bifrontal and right parietal burr-holes were made on March 4. In the right parietal and left frontal regions the dura was normal and the brain looked œdematous. In the right frontal region an extradural collection of pus was found. The infected dura was not opened. A rubber catheter was inserted extradurally for three-hourly injections with 6,000 to 12,000 units of penicillin for seven days. Penicillin $(6,000$ units) was also injected into the left ventricle ; and 40,000 units were given intramuscularly at threehourly intervals for seven days, followed 'by 20,000 units three-hourly for another fourteen.

There was no immediate improvement. While on the table she had numerous left sided focal epileptic attacks resulting in generalized convulsions. She became delirious and therefore, 36 hours after admission, a right frontal flap was turned and a large area of infected frontal bone-reaching from the coronal suture down to and including the roof of the right frontal sinus, which was stripped of its chronically inflamed mucosawas rongeured away. The dura in the whole area thus exposed was covered with thick granulation tissue and with some free pus. This time the dura was incised in two places; from the anterior incision a few c.cm. of subdural pus was aspirated. Two fine rubber catheters were inserted under the dural incisions for instillation of penicillin $(4,000$ units three-hourly). A blood transfusion of 1 pint was given. 

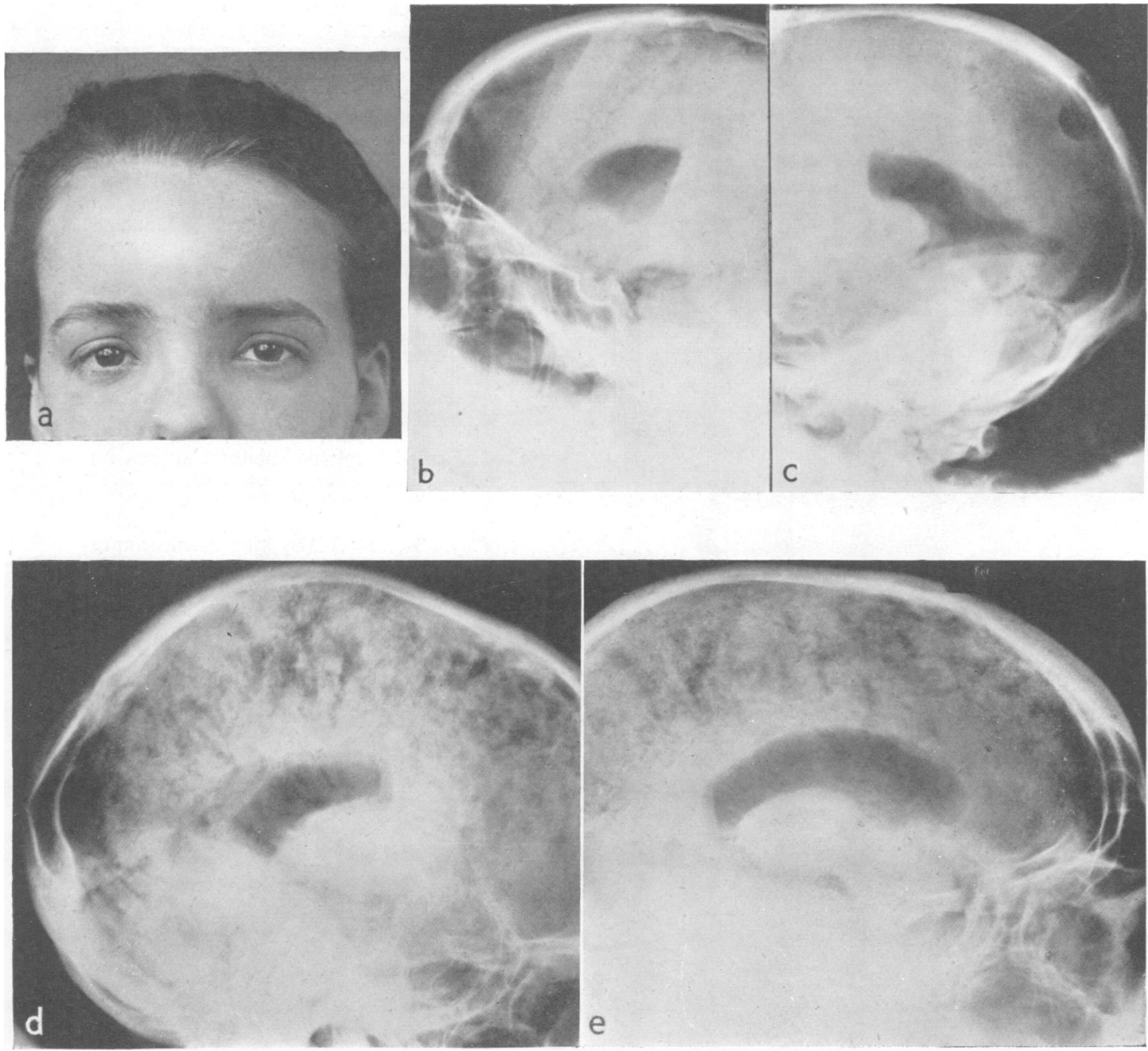

Plate I (a).-Pericranial abscess of the forehead in a case of pansinusitis and chronic focal osteomyelitis of frontal bone with extradural abscess. The infected bone was excised and the abscesses drained. On the morning of operation the patient vomited, and five days after operation she became unconscious. Free subdural pus over the right hemisphere was drained, but she died sixteen days after the first operation. (L.H. 1079.)

(b) and (c).-A case of head injury, with air in the subdural space (and ventricles), (b) face up, (c) face down. In (b) the subdural air is against the frontal bone ; in $(c)$ it is seen behind the posterior horn of the lateral ventricle against the occipital bone. (R.I. 63080/46.)

$(d)$ and (e).-A case of idiopathic epilepsy, with air in the subarachnoid space (and ventricles), $(d)$ face down, $(e)$ face up. The air in the ventricles moves freely with the change of posture but that in the subarachnoid space does not. (R.I. 77325/47.) 


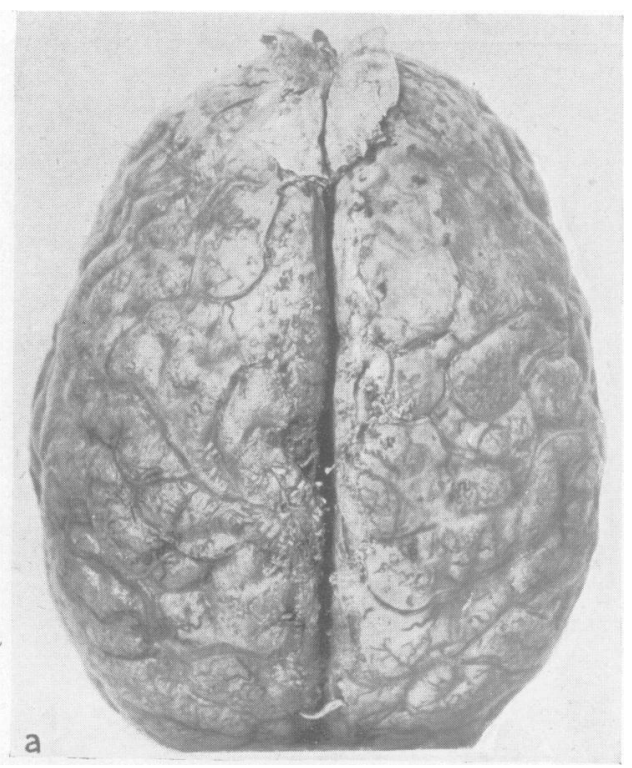

Plate II (a).-The brain from a case of purulent pachymeningitis following pansinusitis and chronic osteomyelitis of the frontal bone. Following external drainage of the left frontal sinus the patient immediately developed signs of purulent pachymeningitis over the right cerebral hemisphere and he died thirteen days later. The figure shows dura adherent to the frontal poles, and behind that, particularly on the right side in the parasagittal region, though to some extent also on the left side, a fibrinopurulent membrane on the outer surface of the arachnoid which obscures the pattern of the underlying convolutions. Section showed also purulent leptomeningitis over the frontal lobes, thrombophlebitis, and gross old and recent softenirig of the underlying brain. (P.M. 31, 1930.)

(b).-Collapsed loculated subdural abscess on medial and inferior surfaces of right cerebral hemisphere as a sequel to purulent pachymeningitis (pneumococcal). (P.M. 234, 1943.) (By kind permission of the Journal of Pathology and Bacteriology.)

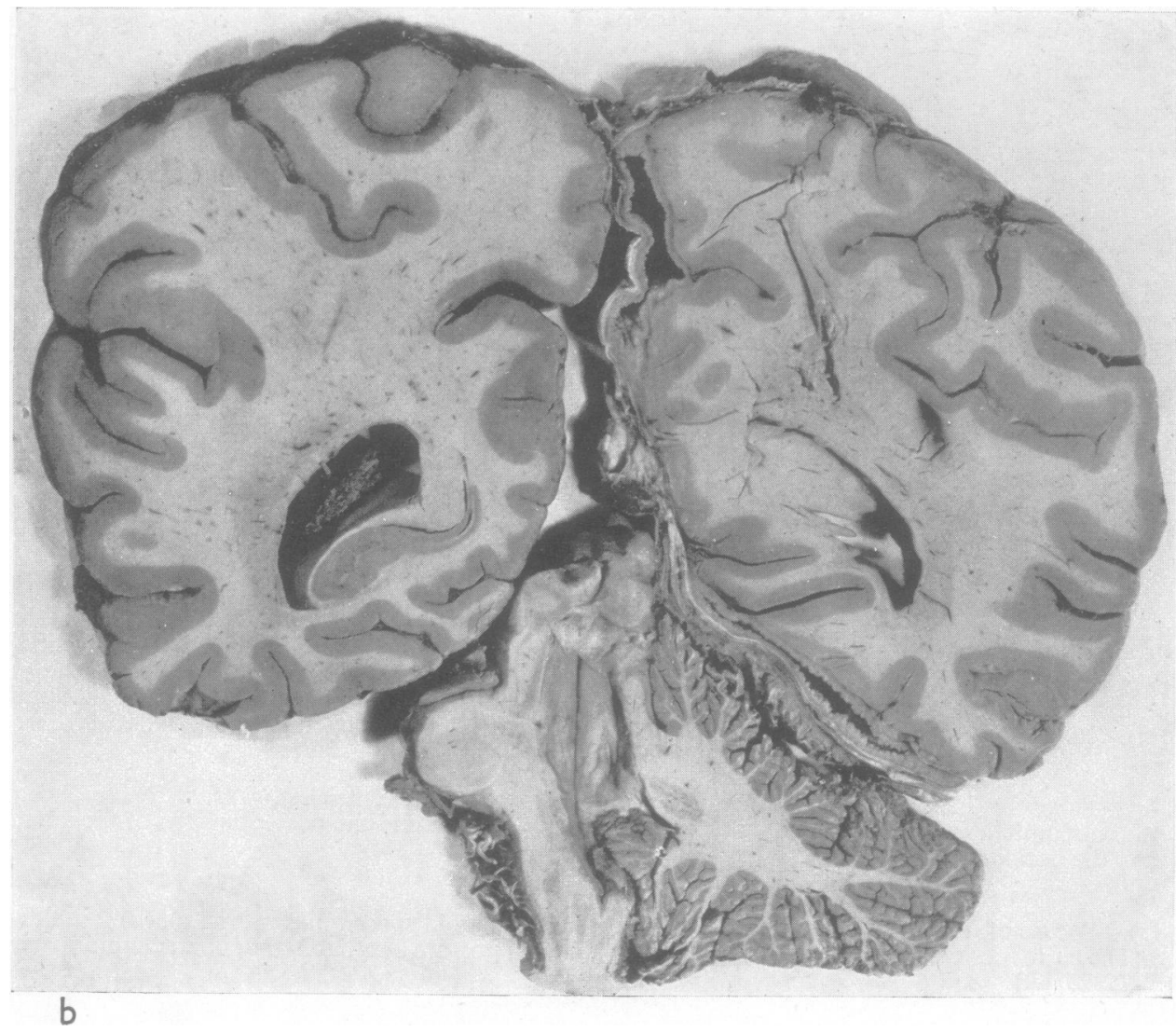




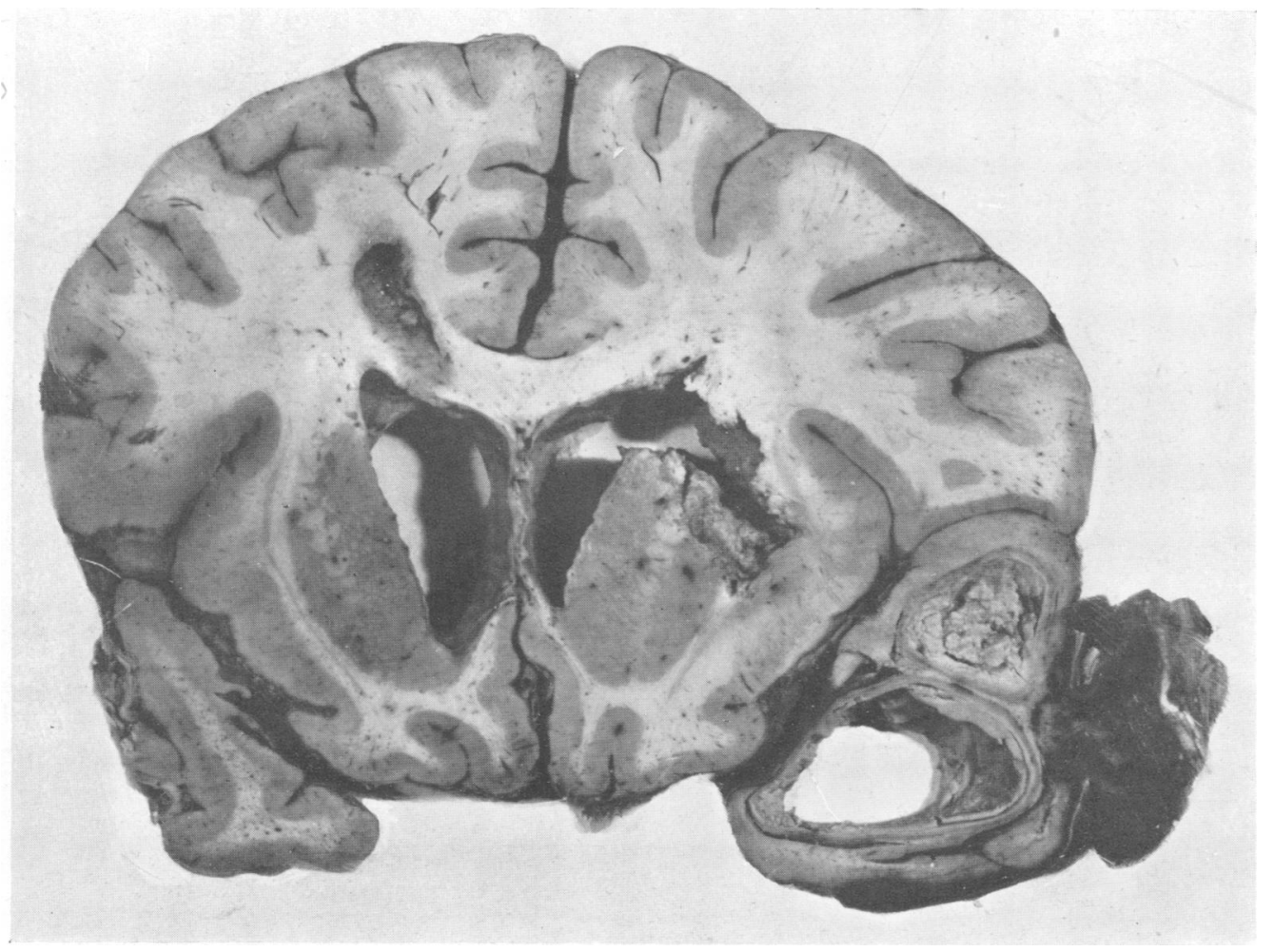

Plate III.--Multilocular abscesses of right temporal lobe following purulent pachymeningitis and loculated subdural abscess. The patient, a man aged 27 years, had chronic pansinusitis for three years treated by multiple operations and antral washouts. He developed spreading osteomyelitis of the right superior maxilla, followed a month later by sudden onset of left hemiplegia and other signs of purulent pachymeningitis. At operation pus (culture, non-hæmolytic streptococcus) was obtained from the subdural space in the right temporal region but not in the parietal region. He was given local penicillin treatment, supplies being inadequate for full systemic treatment. He developed a brain fungus (which can be seen in the figure) and died from ventriculitis due to $E$. coli. Necropsy revealed numerous loculi of pus in the subdural space of the anterior half of the right cerebral hemisphere, maximal at its medial border; a further subdural abscess over the lateral aspect of the left temporal pole ; two cerebral abscesses in the right temporal lobe (shown in the figure) beneath the site of the drained subdural pus and the brain fungus; two abscesses in the right frontal lobe, one near and one at a distance from the temporal abscesses; ventriculitis and purulent leptomeningitis. There were also abscesses in the right pterygoid muscles and a sequestrum in the orbital plate of the right superior maxilla. (P.M. 67, 1944.) 


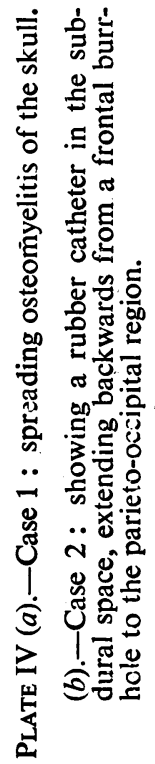


a
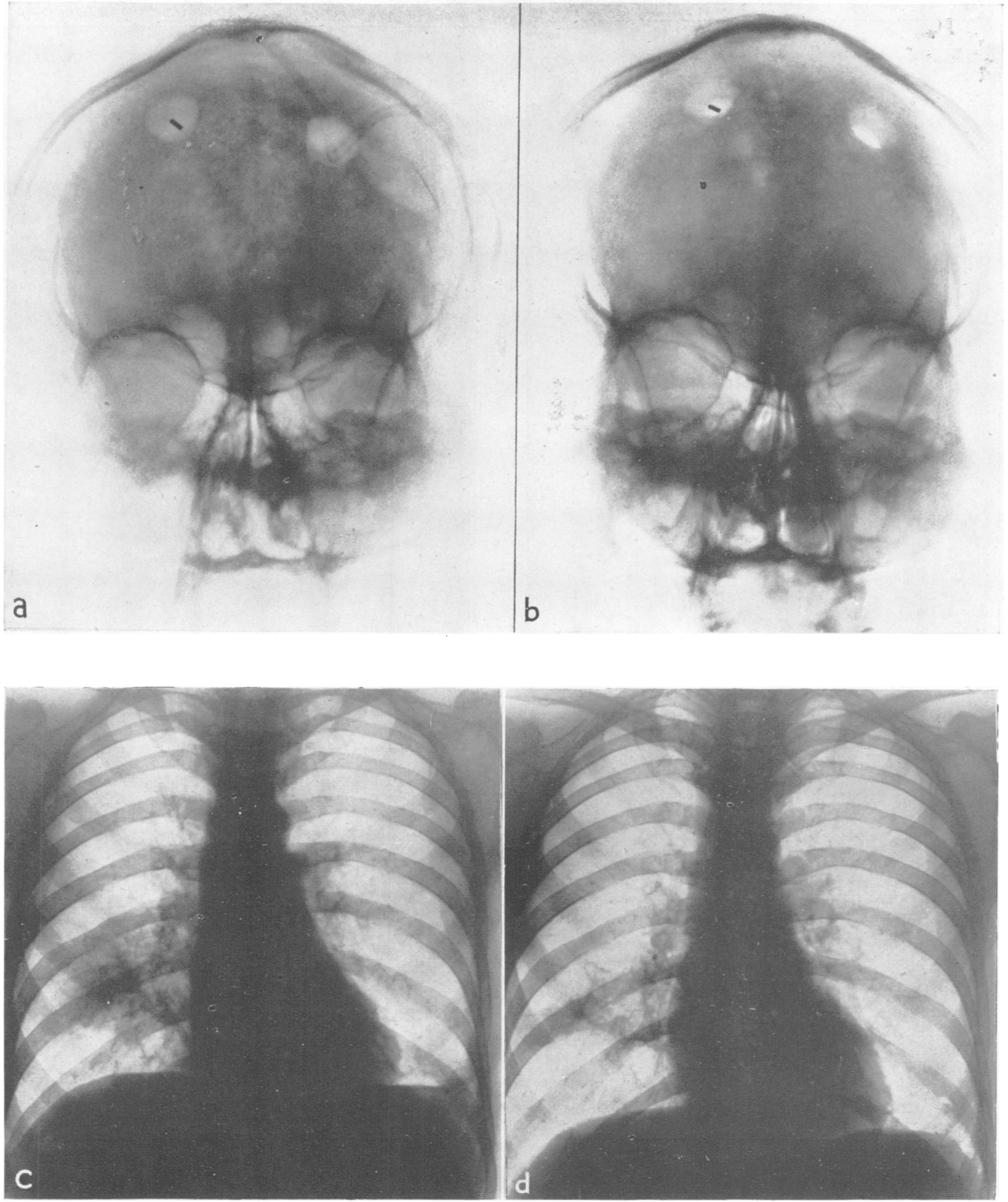

Plate V.-Case 2: osteomyelitis of the frontal bone. (a) in the acute stage (showing also a catheter in the subdural space); $(b)$ six months later the osteomyelitis has cleared up without surgical removal of bone; (c) consolidation of the right lung; $(d)$ ten weeks later. 

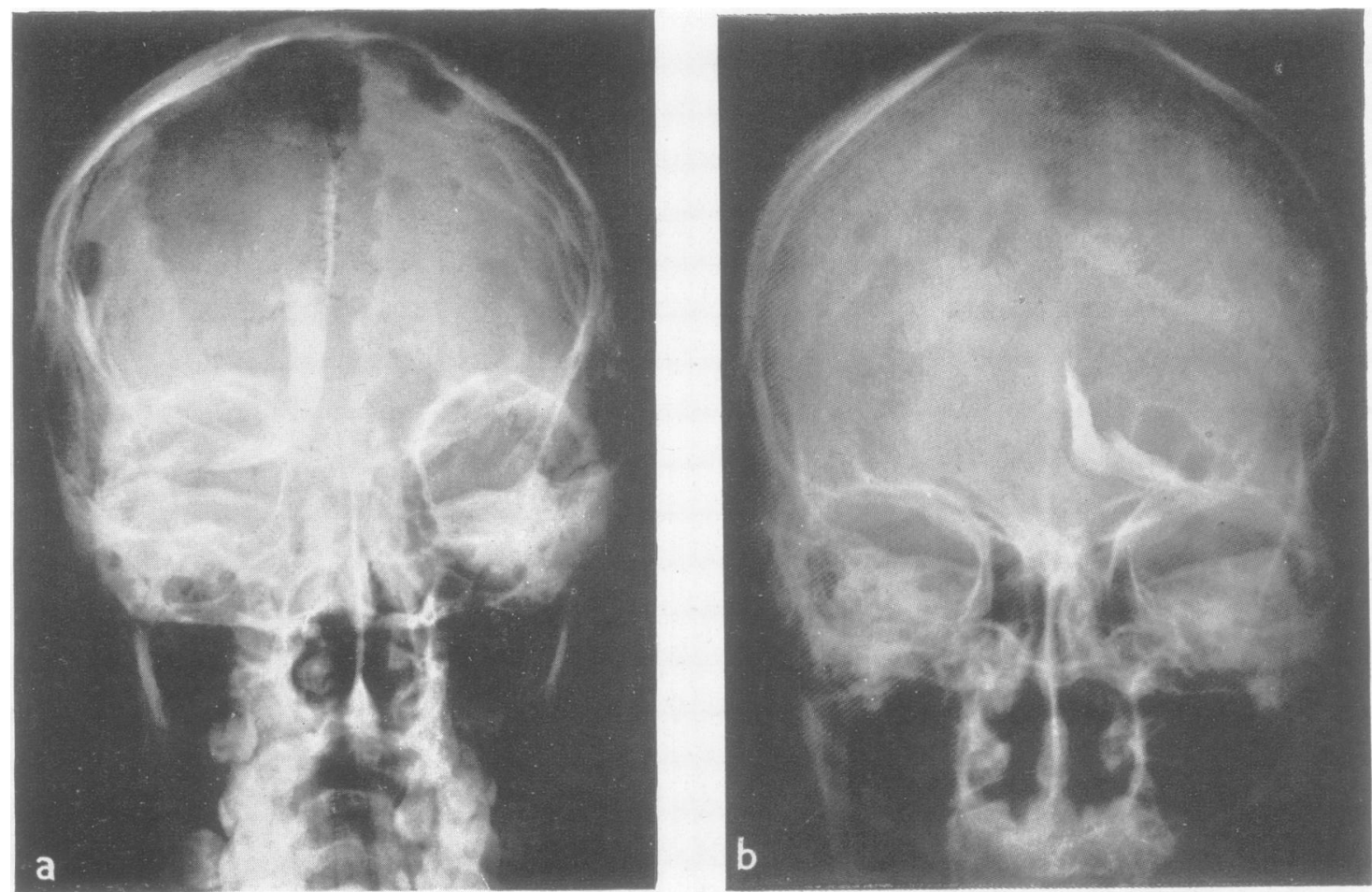

Plate VI (a).-Case 4 : pyogram of right subdural abscess. Note also the defect from removal of osteomyelitic bone.

(b) and (c).-Case 5 : pyograms of loculated subdural abscess, (b) anteroposterior, and (c) lateral, where the thorotrast shows as an irregular ill-defined shadow above the tentorium.

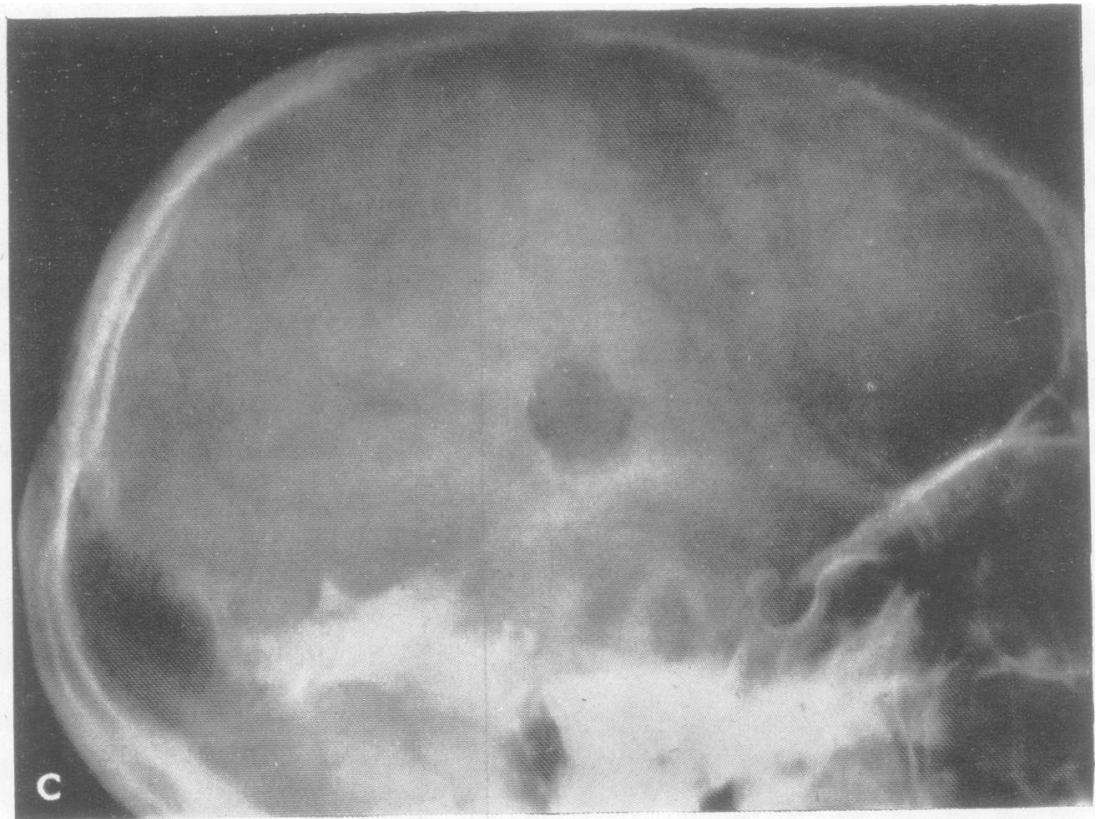




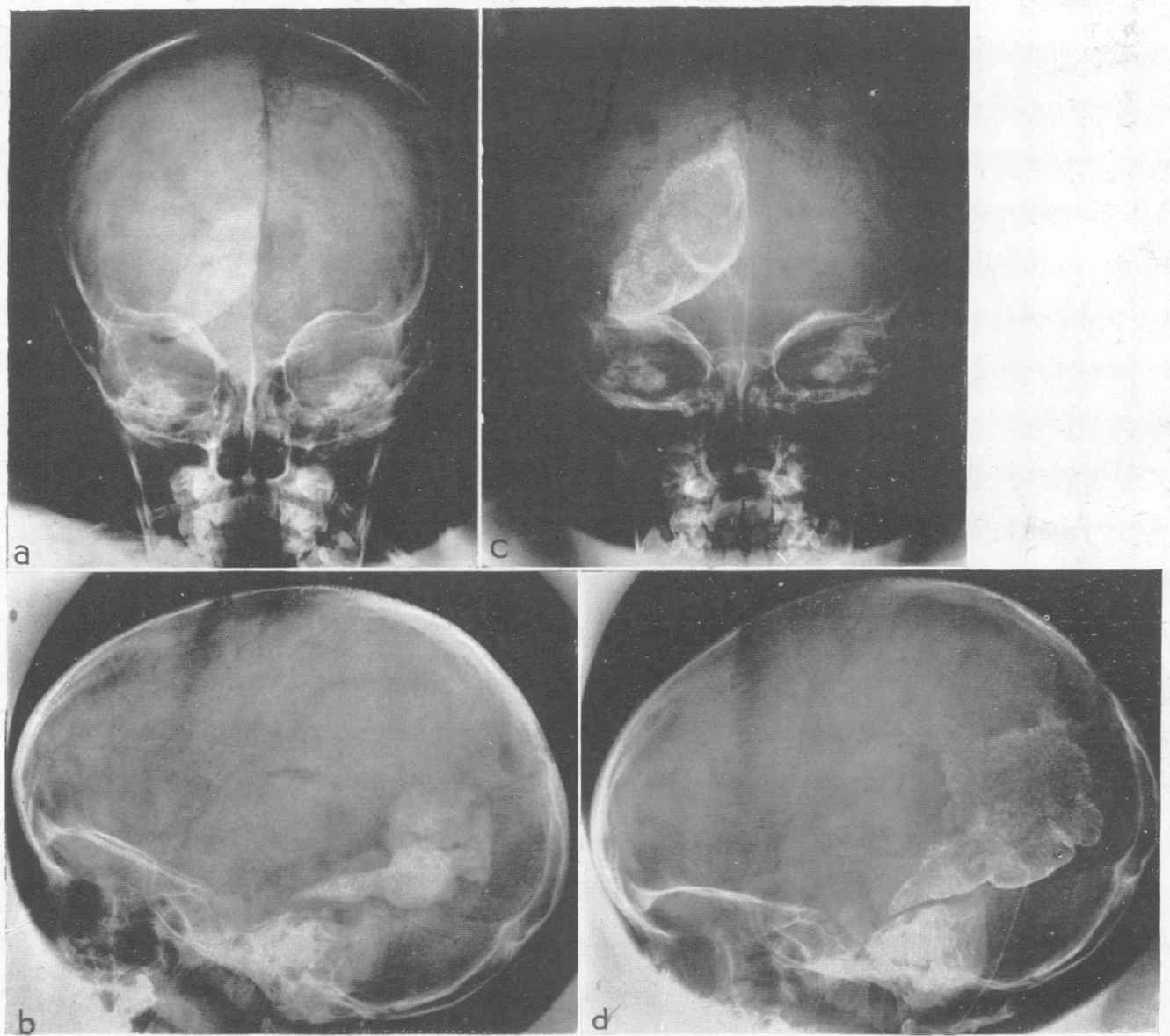

Plate VII.-Loculated subdural abscess in a child of 3 years who had had mastoiditis followed by an abscess in the corresponding middle fossa (? subdural). When she came under our care (1944) she had a brain fungus and the subdural abscess (culture sterile) shown above. There was no hemiplegia associated with this abscess at first. At necropsy there was also a cerebral abscess beneath the fungus and pyocephalus. (a) and (b).-Immediately after injection (May 2). (c) and (d).-Four weeks later (May 31). At no time did this patient have the syndrome of purulent pachymeningitis and the case is not included in the present series. (R.I. 25501/44.) 


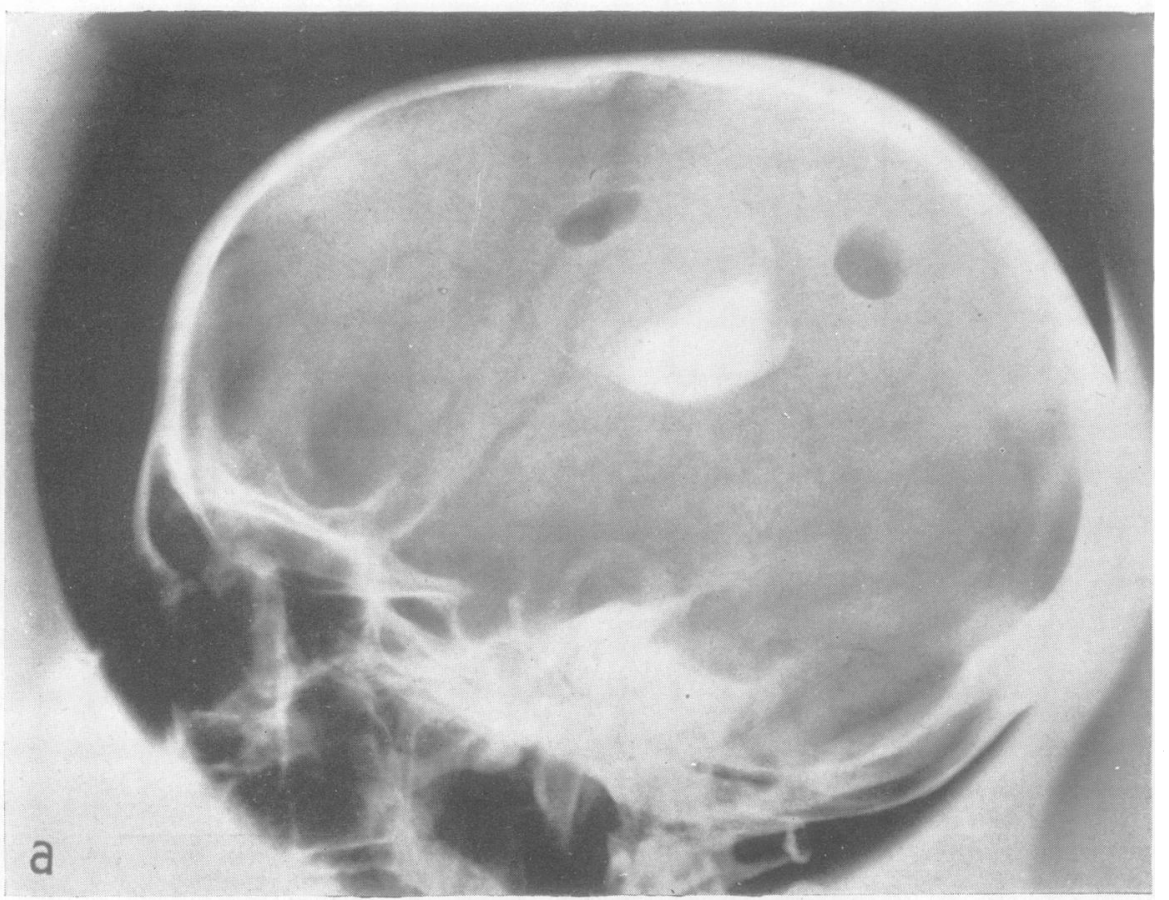

Plate VIII (a) and (b). - Case 6: Thorotrast pyogram of cerebralabscess secondary to loculated subdural abscess.

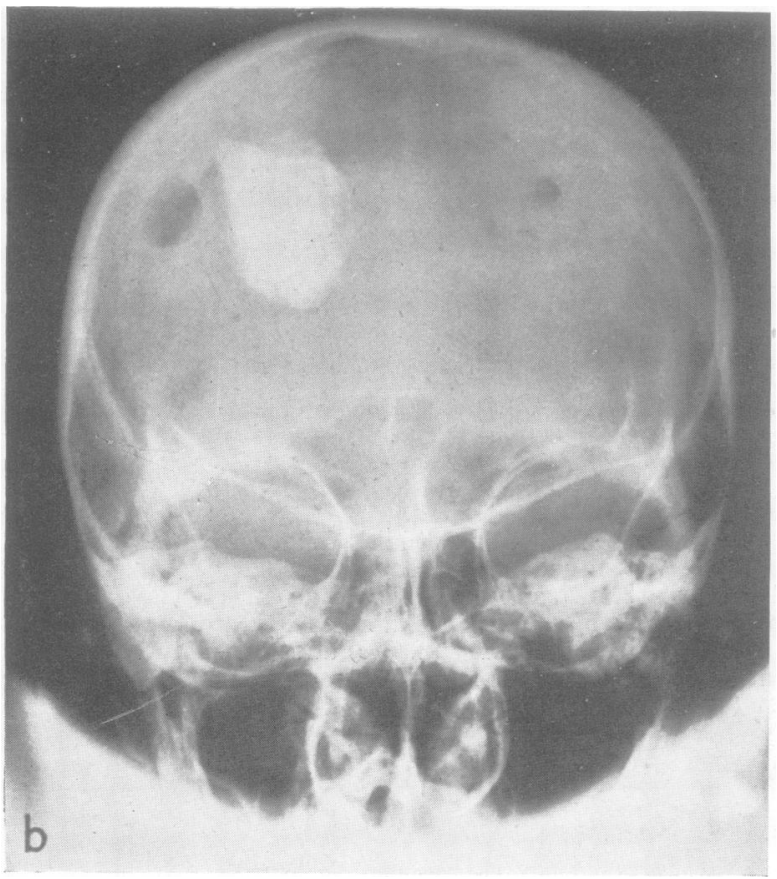

(c).-Case 6: microphotograph of subdural and cerebral abscess. (i) Subdural abscess, (ii) intracerebral abscess, (iii) intervening cerebral cortex.

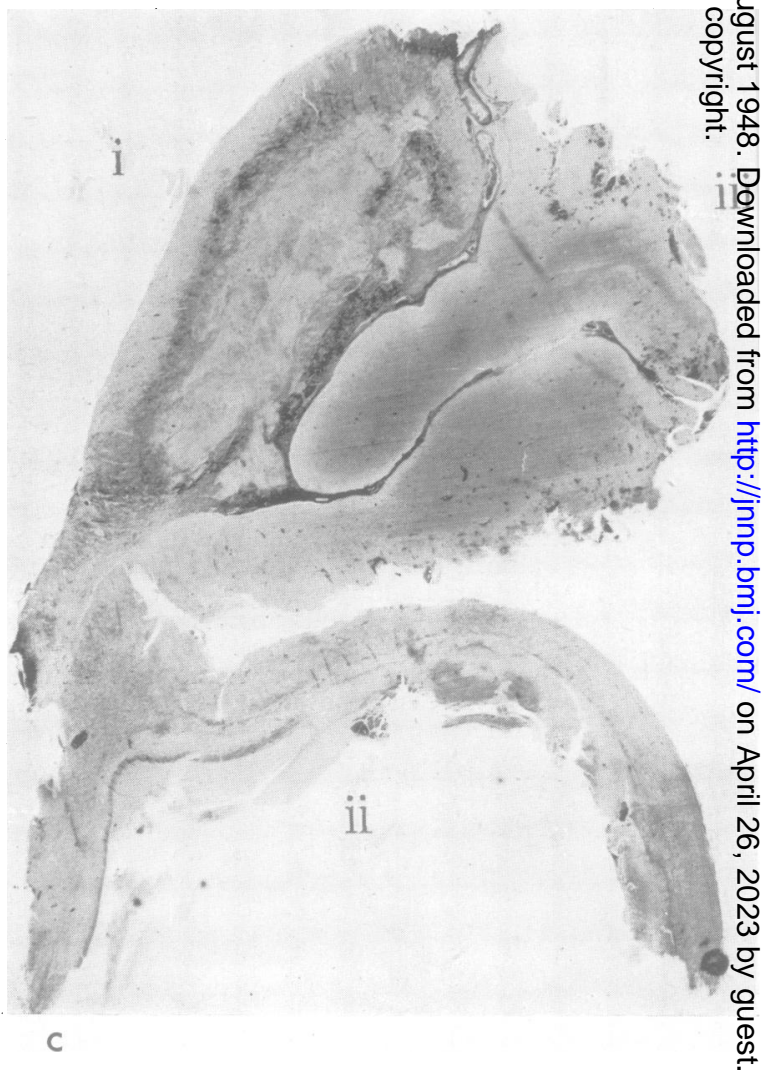



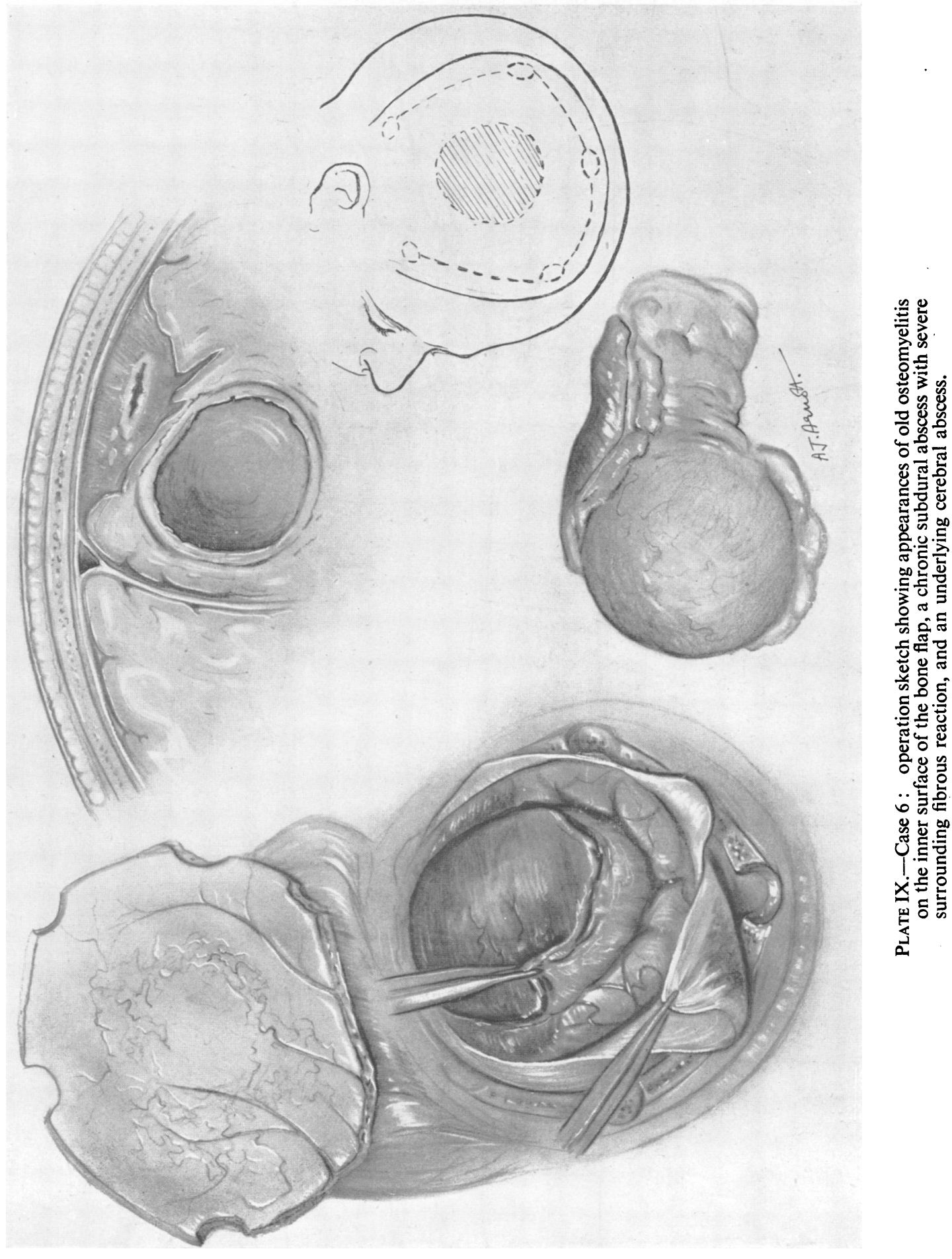


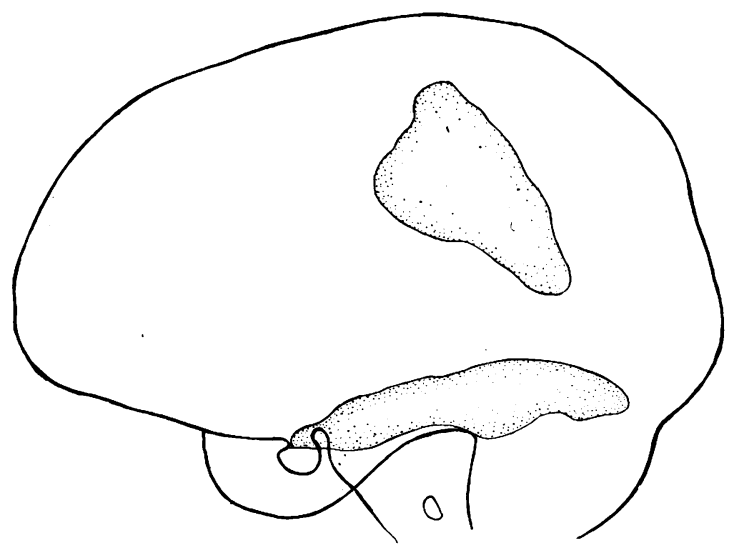

FIG. 2.-Case 3. Air pyogram showing site of subdural abscess on medial and inferior surface of the ieft hemisphere.

FIG. 3.-Case 3. Ventriculography after recovery, showing bilateral symmetrically placed hydrocephalus. The ventricle on the affected left side is the larger.

FIG. 4.-Case 3. Tracing of radiograph, showing osteomyelitis of left frontal bone as it appeared five weeks after the onset of purulent pachymeningitis. It subsided under penicillin treatment without suppuration or removal of bone.

FIG. 2

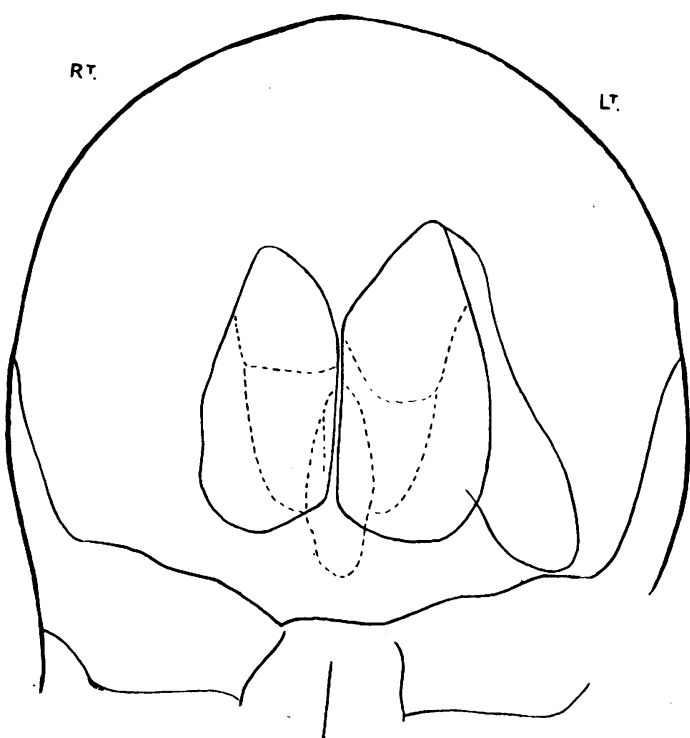

FIG. 3

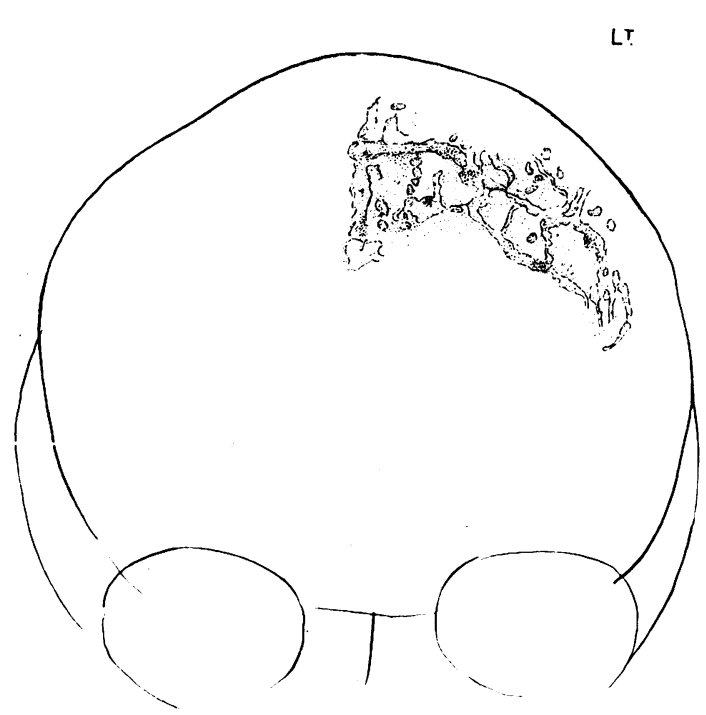

Fis. 4 
Bacteriology.-The organisms from the extra- and subdural pus, seen on films, but not grown in cultures, were streptococci.

Subsequent Course.-Her general physical and mental condition improved slightly. Though confused and drowsy, she recovered from her delirium and fits and became apyrexial on the sixth day ; but there was little improvement of her left hemiplegia, her hemianopia persisted, and the lumbar puncture pressure remained high $(600 \mathrm{~mm}$.). We concluded that she probably had a cerebral abscess. Therefore ten days after admission, on March 15, in an attempt to localize the abscess, right common carotid arteriography was done. The films showed an almost complete obstruction of the common carotid at its bifurcation: there was no filling of the internal carotid or its branches, the external carotid and its branches contained a little of the contrast medium, and there had evidently been a reflux into the subclavian for the vertebral artery was well filled (Fig. 5). This totally unexpected finding may have been due to carotid thrombosis, which could explain the hemiplegia and even the homonymous hemianopia ; but it did not explain the great rise of intracranial pressure, nor did it exclude the presence of an abscess.

On the same day (March 15) the brain was explored with a needle first in the right frontal lobe with negative result, then in the posterior part of the right parietal lobe, where at a depth of $6 \mathrm{~cm}$. pus was encountered and $5 \mathrm{c.cm}$. aspirated. Penicillin (8,000 units) and thorotrast (2 c.cm.) were injected into the cavity. Radiographs showed that the contrast medium outlined the tentorium and falx, that is, that there was a loculated subdural abscess on the base and medial surface of the right occipital lobe (Plate VIa). The pus contained numerous degenerate Gram-positive cocci on films ; cultures were sterile.

On the following day the subdural abscess was approached through another small craniotomy slightly to the right and in front of the external occipital protuberance. A catheter was inserted into the abscess, allowing evacuation of a large quantity of pus, and penicillin was instilled $(6,000$ units, first three-hourly then six-hourly) for four days. As there was no immediate response to this treatment, another right parietal, parasagittal burr-hole was made on March 19, but no further pus was found. Her hæmoglobin had fallen to 46 per cent., so she was given two blood transfusions. On March 21 her lumbar puncture pressure fell, and from then onwards she gradually recovered. One month after admission ventriculography confirmed the disappearance of any space-occupying lesion (Figs. 6 and 7), and pressure and contents of the cerebrospinal fluid were normal. Throughout the course of her illness leptomeningitis had never been severe, nor had any bacteria been seen in her cerebrospinal fluid.

Owing to shortage of beds she was discharged to another hospital on April 6, 1945, still pale, weak, somewhat confused, and bedridden. The left hemiplegia was still virtually complete, there was severe postural loss in the left limbs, and left homonymous hemianopia. In June she was walking and able to leave hospital. In
August, 1945, she showed only slight sensory and motor weakness of the left limbs. When last seen in August, 1947, she was employed in housework. Her visual fields were full, and only very slight traces of the hemiparesis could be found in the left lower limb. She had had no headaches or fits. The right carotid arteries were pulsating normally, suggesting that any obstruction there may have been had now disappeared.

In this case as in the previous one the subdural pus over the convexity of the right hemisphere was successfully dealt with by the initial instillations of penicillin into the subdural space. The patient's hemiplegia, hemianæsthesia, and homonymous hemianopia failed to improve and her intracranial pressure remained very high. A subdural abscess was subsequently found on the medial and inferior surfaces of the right hemisphere.

It will be noted that this patient had seven separate operative procedures in the course of one month : (1) drainage of extra-dural abscess ; (2) removal of osteomyelitic bone and subdural drainage ; (3) arteriography ; (4) needling of loculated subdural abscess; (5) insertion of catheter into subdural abscess ; (6) further exploration of the subdural space; and (7) ventriculography. In retrospect two of these operations, nos. 3 and 6 , might have been dispensed with, but at the time, in view of the grave state of the patient, it seemed essential to learn more of the intracranial pathology, and neither of these operations affected the patient adversely. The point is that unless the whole of the subdural space can be adequately supplied with penicillin at the beginning, and particularly that part of it on the medial and inferior surfaces of the cerebral hemisphere, repeated operations will usually be necessary.

The infecting organism could never be cultivated but morphologically it was a streptococcus. Clinically this case showed a less intense infection than Cases 1 and 2. It differed also in the presence of a definite frontal extradural abscess which was characterized clinically by severe frontal pain. Severe localized pain was not present in uncomplicated purulent pachymeningitis and should be regarded as an indication of an associated extradural abscess.

Another point of note is that notwithstanding the fact that there was an abscess in the subdural space immediately over the calcarine fissure, and that considerable quantities of penicillin were instilled into the abscess (144,000 units in four days) the recovery from homonymous hemianopia was complete; and there were no fits in the next two and a half years.

The carotid obstruction found on arteriography was totally unexpected and we do not know its 


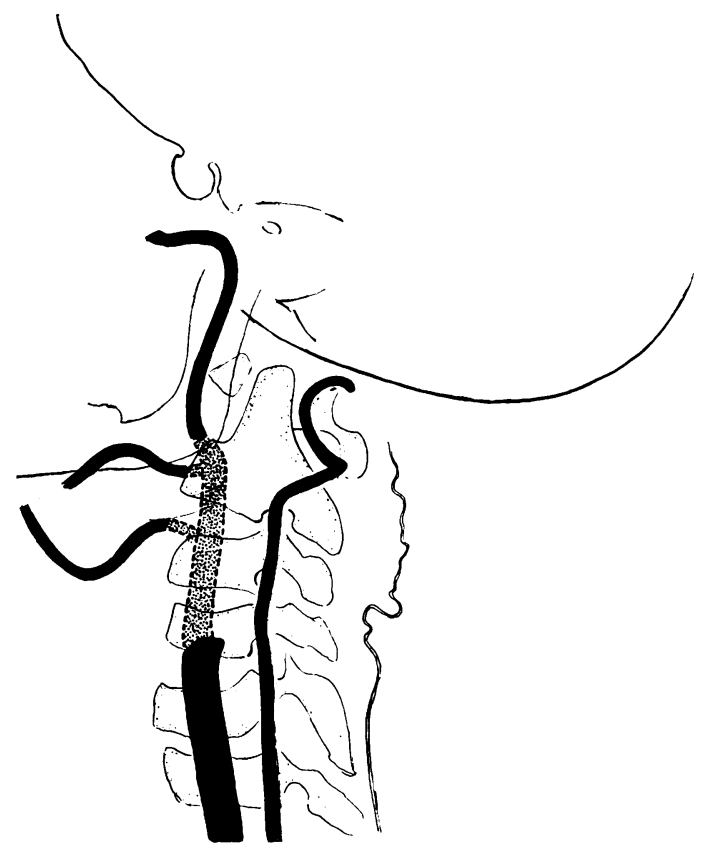

Fig. 5

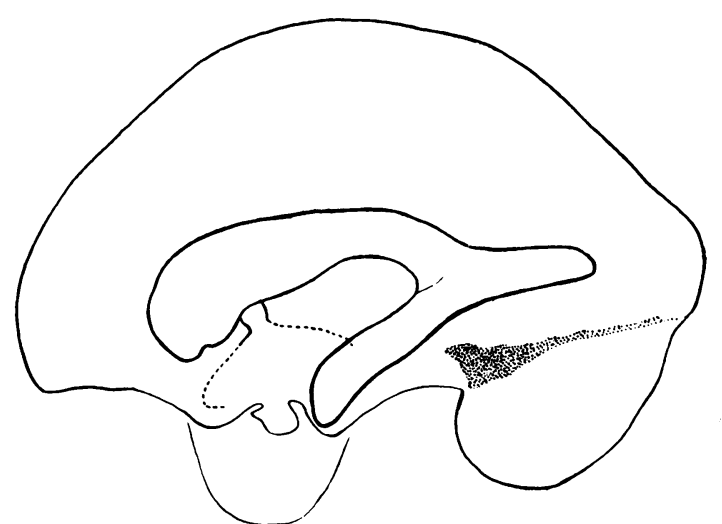

Fig. 7

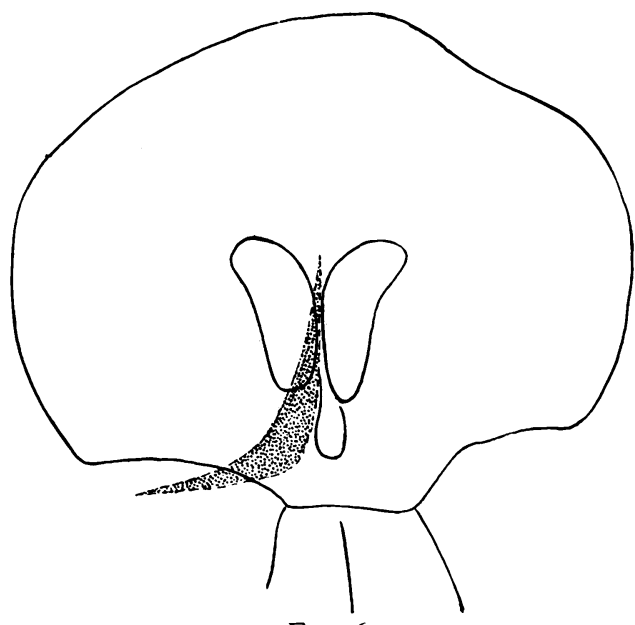

FIG. 6

FIG. 5.-Case 4. Tracing of arteriogram of the right common carotid, showing complete obstruction of internal and partial obstruction of external carotid at the level of the bifurcation. There is reflux of contrast medium into the subclavian artery with resultant filling of vertebral artery.

FIG. 6.-Ventriculogram showing symmetrical slightly dilated lateral ventricles and, indicated by a faint thorotrast shadow, the shrunken capsule of the subdural abscess.

FIG. 7.-Lateral view of ventriculogram shown in Fig. 6. 
cause. - It was probably not due to spasm; with our technique spasm has not been encountered, when, as in this case, the artery is successfully entered at the first puncture; and the patient's blood pressure was not high. We can only suppose that it was due to carotid thrombosis, though the patient is much younger than those described by Gilmour (1941) and Moniz (1941).

The following case is an example of purulent pachymeningitis with loculations following mastoid infection. Although one of the incompletely treated cases, it is included because it illustrates the mode of spread of subdural pus from the mastoid and the difficulties of finding and draining the pus.

Case 5. Left mastoiditis. Purulent pachymeningitis with loculation. Thrombosis of left lateral and other intracranial venous sinuses. Mastoidectomy and ligation of left internal jugular vein. Drainage of subdural pus and incomplete local penicillin therapy. Death. (No. 7699.)

A driver, aged 39, was admitted to the Military Hospital (Head Injuries), Oxford, on Jan. 15, 1944. Eight years before he had had a left incomplete mastoidectomy, and thereafter remained well until Jan. 9, 1944, when he began to have fever (up to $103 \cdot 2^{\circ} \mathrm{F}$.), and pain in the left ear followed by discharge of foul pus from the meatus and swelling of the old operation scar. On Jan. 13 Major Williams performed a radical mastoidectomy and found a subperiosteal abscess in contact with the lateral sinus, which apparently was not thrombosed ; there was also a small extradural abscess above the tegmen.

On Jan. 15 he was drowsy and had some headache, and his temperature rose again to $103 \cdot 5^{\circ} \mathrm{F}$. Lumbar puncture with unilateral jugular compression showed a partial left jugular block suggesting a mural thrombus (protein $80 \mathrm{mg}$. per $100 \mathrm{c.cm} ., 100$ white cells per c.mm.), and so the left internal jugular vein was tied. On the same evening he was transferred to Oxford.

On admission he was drowsy, confused, and showed slight nominal dysphasia. Temperature was $102 \cdot 2^{\circ} \mathrm{F}$., rising to $104^{\circ}$, pulse rate 108 , respirations 22 per minute. To confrontation there was a partial right upper quadrantic homonymous hemianopia and he had slight right lower facial weakness and slight weakness, clumsiness, and flaccidity of the right upper limb. His mastoid wound was clean. Lumbar puncture yielded clear fluid under a pressure of $180 \mathrm{~mm}$. cerebrospinal fluid protein was $70 \mathrm{mg}$. per $100 \mathrm{c.cm}$., white cells 150 per c.mm. (predominantly polymorphonuclear), films and cultures sterile. He was put on a course of sulphadiazine.

In the following days he was at times drowsy and at times complaining of severe pain in the region of the left mastoid wound and in the forehead. On Jan. 22 his aphasia was worse. Later in the day he had a rigor, with rise of temperature from $103^{\circ}$ to $106^{\circ} \mathrm{F}$., and after this he became comatose and did not move his rignt arm or leg. His lumbar cerebrospinal fluid was unchanged, though its pressure was now over $300 \mathrm{~mm}$. Blood culture was sterile. It was thought that he had infective thrombophlebitis with purulent pachymeningitis.

Operation.-On Jan. 22 a left temporal burr-hole showed a thrombosed cortical vein, but no subdural pus on the outer aspect of the temporal lobe. However, a needle passed through the temporal lobe to the medial part of its inferior surface encountered $10 \mathrm{c.cm}$. of pus, and injection of $2 \mathrm{c.cm}$. of thorotrast at this point showed that the pus was in the subdural space alongside the falx and beneath the temporal lobe (Plate VI b and c). The thorotrast was mobile. Another small hole was now made above the left lateral sinus, the occipital lobe was retracted from the tentorium, and a further $10 \mathrm{c.cm}$. of pus was obtained. A catheter was laid in the abscess area for instillations of penicillin $(3 \mathrm{c.cm}$. of solution, 500 units per c.cm. at eight-hourly intervals). Owing to shortage of supplies no penicillin could be given systemically.

Bacteriology.-The subdural pus showed pus cells and intra-cellular Gram-positive cocci on films; ærobic cultures were sterile, but anærobic cultures grew a shortchained streptococcus.

Subsequent Course.-The patient improved for three days, regaining some power in his right limbs, but on Jan. 26 he suddenly became unconscious and showed a dilated fixed pupil on the left side and extensor rigidity of the right limbs. A burr-hole was made over the left parietal lobe alongside the sagittal sinus but the subdural space there contained no pus. The site of the subdural drain was also explored again, but only a small amount of pus was found. The left temporal lobe was also explored by brain needle without disclosing any abscess. The patient died on Jan. 28.

Necropsy (P.M. 53, 1944).-Macroscopic.-A few old pleural adhesions; patchy bronchopneumonia of the lower lobes of both lungs; slightly enlarged septic spleen, and fatty degeneration of the liver. The left jugular vein contained an infected thrombus extending down to within $1 \mathrm{~cm}$. of the site of ligature. Most of the anterior part of the left petrous temporal bone showed osteomyelitis, but there was no naked-eye evidence of osteomyelitis in other parts of the skull. There were infected thrombi attached to the walls of the left sigmoid sinus $(1.7 \mathrm{~cm}$. by $0.5 \mathrm{~cm}$.), the left lateral sinus ( $1 \mathrm{~cm}$. long), and the sagittal sinus (one $2 \mathrm{~cm}$. long in the posterior parietal region, another $0.6 \mathrm{~cm}$. diameter at the Rolandic level). There were patches of friable red and grey clot lightly adherent to the walls of the torcular and the adjacent $1 \mathrm{~cm}$. of the straight sinus, and red clot, probably ante-mortem, in the posterior intercavernous sinus. The left Rolandic vein was partly occluded by yellow thrombus at a point $6 \mathrm{~cm}$. from sagittal sinus.

In the subdural space a layer of thick pus coated the whole of the left side of the falx and the upper surface of the left side of the tentorium, and extended over the anterior half of the convex surface of the left cerebral hemisphere, the left frontal pole, and the posterior third of the inferior surface of the left frontal lobe. A similar layer of pus covered the central $9 \mathrm{~cm}$. of the right side of the falx. Beneath the pus the brain was covered by a 
shaggy film of fibrino-purulent membrane and was irregularly indented. On the left side the subdural collection formed two main pockets on the medial aspect of the hemisphere, one parietal $(5.5 \mathrm{~cm}$. by $5.5 \mathrm{~cm}$. by up to $1.5 \mathrm{~cm}$. deep), the other frontal $(5.5 \mathrm{~cm}$. from before back by $3 \mathrm{~cm}$. from above down by up to $1 \mathrm{~cm}$. deep). On the right side there was a pocket of pus on the medial side of the parietal lobe $(8.5 \mathrm{~cm}$. from before back by $5 \mathrm{~cm}$. from above down by $0.5 \mathrm{~cm}$. deep). There was a further pocket of pus at the left frontal pole $(3 \mathrm{~cm}$. by $2 \cdot 2 \mathrm{~cm}$. by $1 \mathrm{~cm}$. deep). In places at the margins of the pockets the dura was lightly adherent to the leptomeninges. The only signs of leptomeningitis were yellow opacity of the arachnoid over the floor of the third ventricle and faint milky opacity of the cisterna magna.

The convolutions of the convex surface of the left hemisphere were broad and flattened. There was severe symmetrical downward herniation of both hippocampal gyri, with lateral compression of the brain stem and narrowing of the aqueduct of Sylvius, and moderate herniation of the cerebellar tonsils. The left lateral ventricle was compressed, the right of normal size. There were fragments of clot in left lateral and fourth ventricles and a recent hæmorrhage $(0.2 \mathrm{~cm}$. diameter) in left pulvinar.

Microscopic.-Organized clot was seen in the left sigmoid and in the sagittal sinus; in the former were a few, in the latter abundant Gram-positive cocci, many of them within the cytoplasm of phagocytes.

Over the left parietal lobe the dura showed laminated thrombus in the larger meningeal veins. Between the dura and arachnoid there was a thick coat of degenerating leucocytes containing small clumps of Gram-positive cocci ; in the thickened leptomeninges there was great proliferative activity and much fibrin, but no bacteria. The subjacent cortex showed similar reaction, and there was degeneration of the cortical cells.

The left Rolandic vein contained unorganized thrombus, and there was a moderate inflammatory reaction in the adjacent meninges but no gross abnormality of the surrounding cortex.

This case is an example of the difficult group in which infection of the subdural spaces arises from the petrous bone and is associated with thrombosis of the lateral sinus. Notwithstanding surgical treatment of the mastoid within one week of the onset of acute symptoms, the subdural space became infected. Aphasia and homonymous hemianopia were the first symptoms. Subdural pus was found on needling the temporal lobe, and might easily have been diagnosed as a cerebral abscess but for the characteristic appearance of the thorotrast pictures (Plate VI b and $c$ ). The subdural pus was not fully drained; nor was the subdural space adequately irrigated with penicillin solution. When three days later the patient suddenly became worse, a search for subdural loculi was made in the usual place, but none was found. This indicates the difficulty of exploring the subdural space, alongside the falx.
After death, which was due to the severe rise of intracranial pressure, it was found that the pus had spread widely in the subdural space, not only on the side of the original lesion but also over the opposite hemisphere. The order of spread was from the inferior surface of the left temporal lobe to the left side of the falx ; then to the inferior surface of the left frontal lobe and to the right side of the falx. The convexity of the brain escaped, except at the left frontal pole.

The part played by thrombosis of the large venous sinuses was at the time difficult to assess ; in retrospect there can be little doubt that in such cases there should be a direct surgical attack upon the clot. In this case matters were made more difficult by the fact that at the time penicillin was in short supply and there was only enough available for local instillations into the subdural space. These were given at too infrequent intervals in view of what we have since learned about penicillin in the subdural space.

Diagnosis of Loculated Subdural Abscess.-In our fifteen cases of purulent pachymeningitis treated by penicillin there have been nine cases of loculatedo subdural abscess (Tables VI and VII). Three of these were associated with cerebral abscess and will be considered more fully in the next section. $\mathrm{OP} \underline{\underline{B}}$. the other six, five were verified by operation and pyography (subsequently confirmed by necropsy in three cases). In the remaining case the lesion was क suspected on clinical grounds and on the ventricus. lographic and arteriographic appearances, but the symptoms subsided during prolonged systemic treatment with penicillin and so it was not verified.

Whether secondary to paranasal sinus or to mastoid disease, the favourite site for subdural loculation was alongside the posterior half of the falx and on the adjacent tentorium of one or both sides, though loculation could also occur on the convexity (Case 6). If unilateral the abscess was usually on the side of the original purulent pachymeningitis, though not invariably (Plate II b).

There may be more than one loculus, but multiple loculi are usually in continuity. The symptoms produced by loculated abscess were most commonly a recurrence of the initial sensori-motor hemiplegia with homonymous hemianopia in the second to fifth week after first drainage of subdural pus ; or the hemiplegia failed to improve after the initial $\bigcirc$ treatment of the purulent pachymeningitis. Thus, the loculus does not usually produce new localizing signs. Intracranial pressure as measured by lumbar puncture steadily increased to levels of $600 \mathrm{~mm}$. of $\cong$ water or more, and there were other signs of raised $N$ pressure : papillœdema, increasing drowsiness, and $\underset{\mathrm{W}}{\mathrm{N}}$ 
deterioration of the patient's general condition. On this basis further surgical explorations were undertaken.

These symptoms were probably kept in check to some extent by continued systemic penicillin, for in three cases they only became evident after penicillin was stopped, and in three other cases the symptoms were entirely suppressed by penicillin, though in two of these the patient subsequently developed a cerebral abscess. The common loculated subdural abscess alongside the falx produced a characteristic deformity of the ventricles (Figs. 8a and $b$ and $9 b$ and $c$ ), and arteriograms in one probable case showed localized depression of the calloso-marginal vessels (Fig. 9a). However, the diagnosis can only be made with certainty in life by thorotrast or air pyograms after needling and aspiration of the abscess (Figs. 2 and $8 \mathrm{c}$ and $\mathrm{d}$; and Plates VI a, b, c, and VII). The appearances are characteristic: in the antero-posterior view the medial and inferior borders of the thorotrast shadow correspond to the falx and tentorium; in the lateral projection the upper surface of the tentorium is sometimes outlined, but otherwise the thorotrast shadow assumes bizarre shapes. After a few days the thorotrast is taken up by the macrophages of the abscess wall, and eventually in radiographs is seen to have a strikingly crenated outline (Plate VII ; also Tutton and Shepherd, 1948).

Before we realized the true nature of this condition we thought when we encountered pus in these cases after needling deeply in the parietal lobe that we were dealing with an abscess deep in the brain substance, or pyocephalus of the lateral ventricle. And when the patient failed to improve we continued to search by needle for intracerebral collections. But the pyograms of subdural abscess are unmistakable, since the abscess is outlined medially and inferiorly by the falx and tentorium. The site of the abscess seems to be approximately the same in the cases arising from mastoid infection as in those from infection of the paranasal sinuses. It is important to realize that loculated subdural abscess can arise in this situation not only as a result of purulent pachymeningitis, but also as a sequel to brain abscess (Plate VII).

With systemic penicillin therapy small subdural loculations may not give rise to complete hemiplegia and may escape notice in patients about to be discharged from hospital as apparently cured, unless ventriculography is performed in such cases as a routine before discharge.

Subdural Loculation with Delayed Cerebral Abscess.-This condition can best be described by the following case report.
Case 6. Perforation of pelvic colon. General peritonitis followed by pelvic abscess. Osteomyelitis of skull and pericranial abscess followed by symptoms of purulent pachymeningitis; relieved by systemic penicillin. Recurrence of symptoms four weeks after cessation of penicillin treatment. Operative removal of old subdural abscess and cerebral abscess (Streptococcus viridans). Recovery, with severe residual symptoms. (R.I. 70609, 1947.)

A woman aged 45 developed generalized peritonitis on Oct. 25, 1946, due to perforation of the pelvic colon by a hare bone. She was treated within a few hours by peritoneal drainage and temporary cacostomy. During November a large pelvic abscess developed: it was drained suprapubically, and it also discharged through the rectum and vagina. She did well and left hospital on Dec. 27, 1946. On Jan. 1, 1947, she developed severe headache, stiff neck, and rigors. A swelling formed on the right side of the head and she was readmitted to hospital on Jan. 4, when she was found to have a fluctuant swelling in the right fronto-parietal region, left facial weakness, dullness and crepitations at the base of the right lung, and some pelvic tenderness. Lumbar puncture gave cerebrospinal fluid containing 10 lymphocytes per c.mm. and $160 \mathrm{mg}$. of protein per 100 c.cm.

She was treated with systemic penicillin $(50,000$ units three-hourly until Jan. 16) and, on Jan. 8, 5 c.cm. of pus was aspirated from the swelling on the head: nonhæmolytic streptococcus and Staphylococcus albus were cultured. On Jan. 9 the patient had weakness of the left upper limb and left side of the face, which gradually increased. On Jan. 12 she had several epileptic attacks, after which her hemiplegia was complete. During the next ten days the hemiplegia improved slowly. On Jan. 25 the frontal swelling recurred, she became drowsy and incontinent of urine and freces, and her optic discs were slightly swollen; systemic penicillin was resumed and $5 \mathrm{c.cm}$. of pus was again aspirated from the frontal swelling. During February her symptoms cleared up and she was discharged from hospital on March 1. Her lumbar cerebrospinal fluid remained unchanged apart from an increase of its resting pressure.

She remained well for about four weeks and then once more developed weakness of the left arm and leg which became complete within a few days. She became apathetic and confused and was admitted to the Radcliffe Infirmary on April 9.

On admission the patient was stuporous and incontinent but her general condition was good. Temperature was normal, pulse rate 80 per minute. Her neck was moderately stiff and Kernig's test was slightly positive. There was slight papillœdema, inattention in the left homonymous visual fields, and flaccid left hemiplegia, complete in the upper limb, almost complete in the lower limb, with increased tendon jerks and an extensor plantar response on the left side. The lumbar cerebrospinal fluid had a pressure of over $300 \mathrm{~mm}$., and contained $130 \mathrm{mg}$. of protein per $100 \mathrm{c.cm}$., and 26 white cells per c.mm. Radiographs showed an area of osteitis in the right frontal region, but her scalp was now healthy. It was thought that she was not sufficiently 

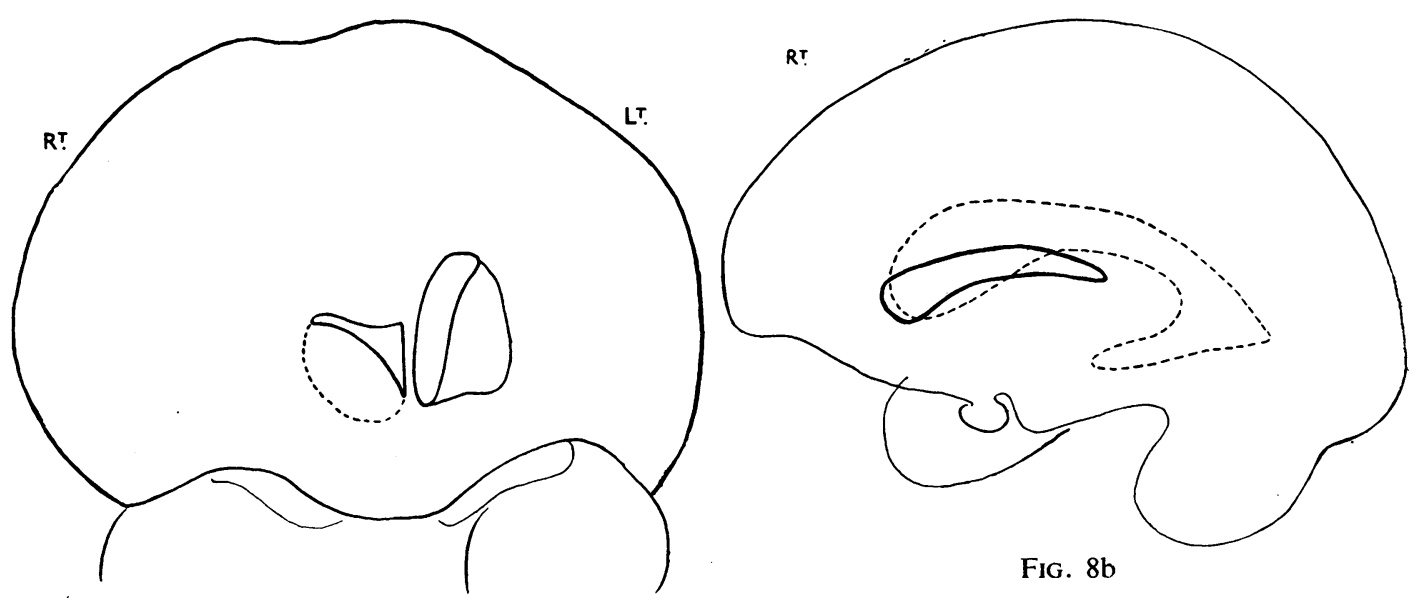

Fig. 8b

FIG. 8a
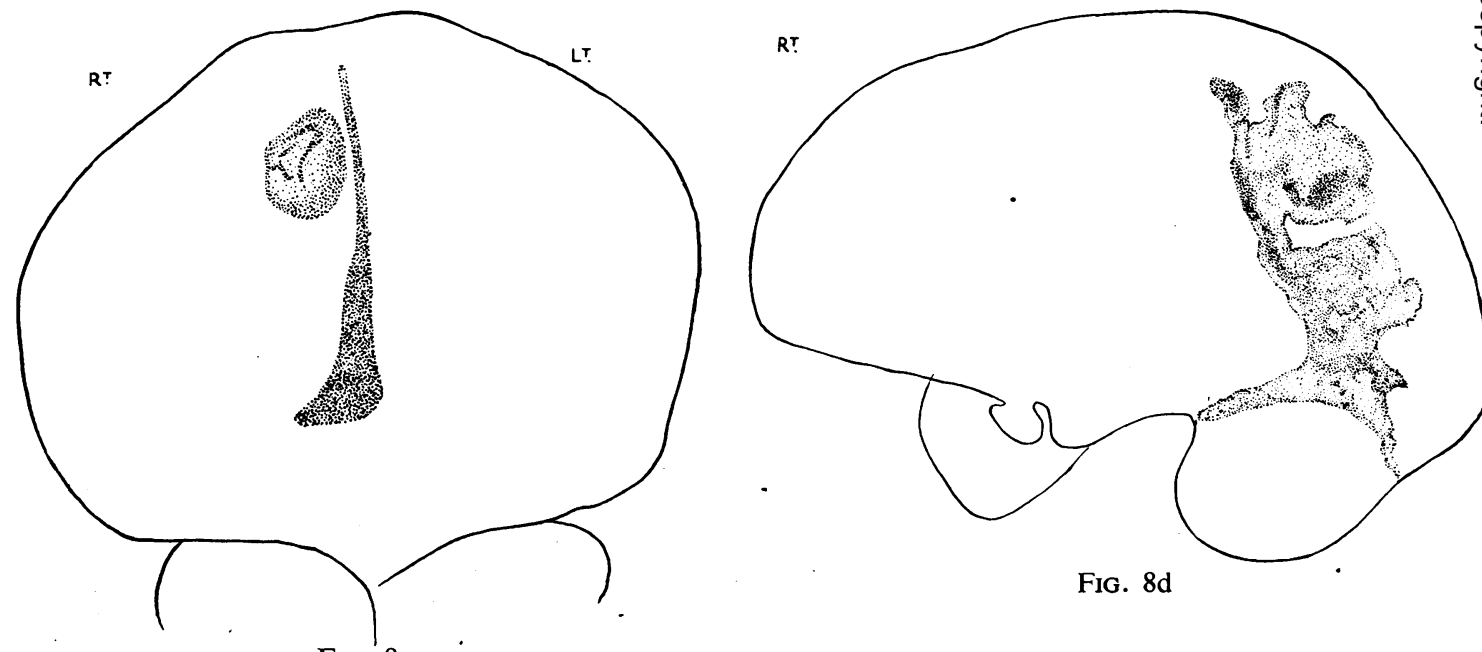

FIG. 8d

FIG. 8c

Fig. 8 a-d.-Ventriculograms and pyograms of a proved case of loculated subdural abscess after purulent pachymeningitis. The brain of this case is shown in Plate II (b). 


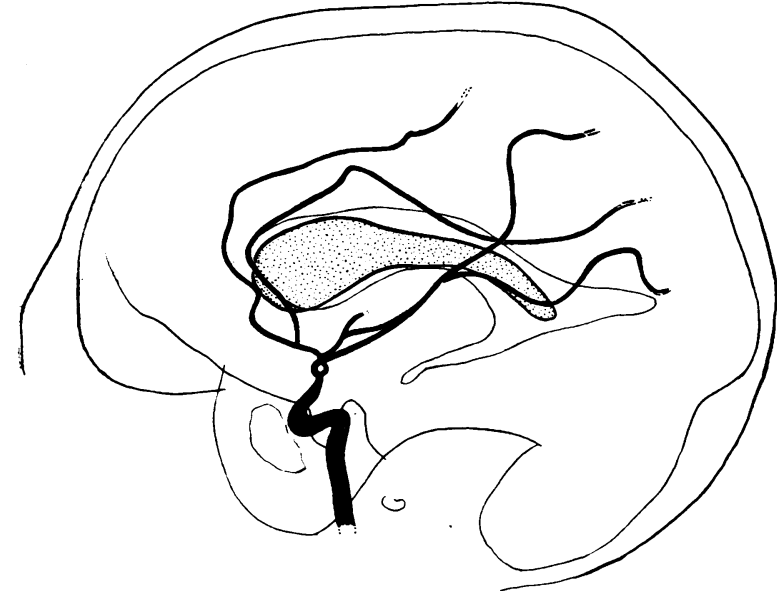

Fig. 9a

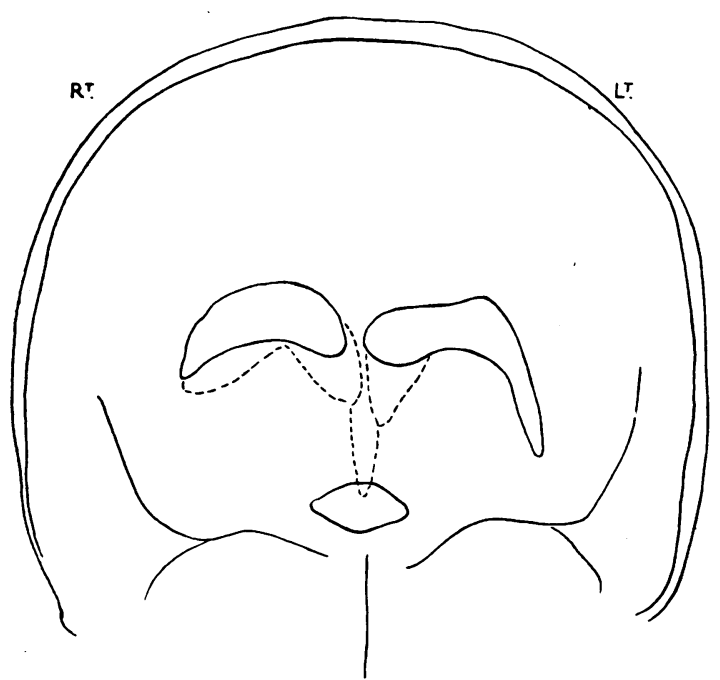

FIG. 9 a-c.-Tracings of encephalogram and arteriogram of an unverified case of a small loculated subdural abscess on the medial surface of the left cerebral hemisphere. The body of the left lateral ventricle and the adjacent left pericallosal artery are depressed from above. The ventricular system is only slightly displaced to the right, indicating that the collection is a small one. (R.I. 67032.)

FIG. 9c

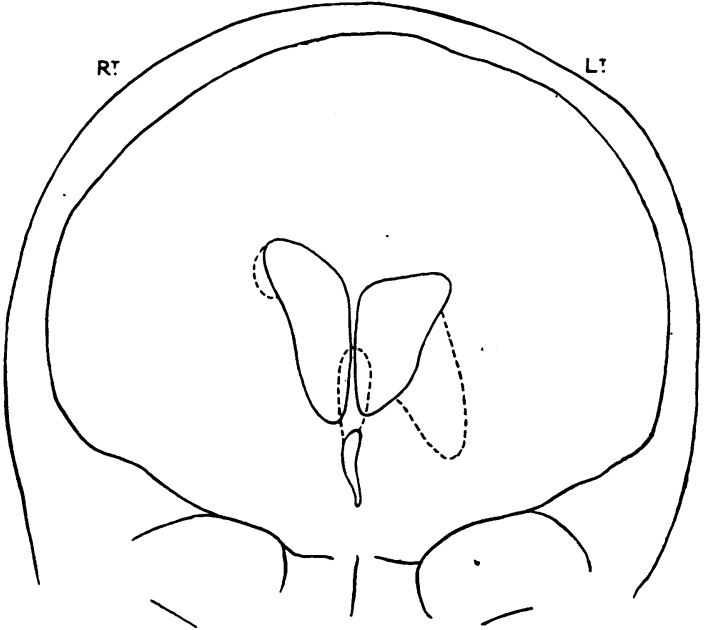

Fig. 9b 
ill for a subdural abscess and that she probably had an intracerebral abscess. She was given systemic penicillin 250,000 to 400,000 units daily.

Angiography showed depression of the right middle cerebral artery and displacement of the right anterior cerebral artery to the left, appearances which indicated an expanding right frontal lesion.

On April 10, through a burr-hole at the right parietal eminence, an abscess was encountered in a forward direction in the frontal lobe : $40 \mathrm{c.cm}$. of pus were removed and 100,000 units of penicillin and $3 \mathrm{c.cm}$. of thorotrast injected (Plate VIII a and b). Streptococcus viridans were found in films and culture.

After this operation she regained consciousness and was found to have left homonymous hemianopia, inability to follow with her eyes an object moving to the left, and gross impairment of postural sensibility in the left limbs. Her left limbs were still very weak and now spastic. She was also emotionally labile, unduly euphoric, and still incontinent. On April 25, as the abscess had increased in size, as shown by radiographs, it was tapped again : $20 \mathrm{c.cm}$. of pus were aspirated. Films showed no organisms, and culture was sterile.

On April 29, 1947, the abscess was removed through an osteoplastic flap (Plate IX). The parietal bone showed evidence of old osteomyelitis. In the subdural space there was a tough membrane, up to $0.9 \mathrm{~cm}$. thick, covering the whole of the area of exploration and densely adherent to the overlying dura and to the cortex beneath. This membrane contained in the central part of the exposed field a localized, collapsed, slit-like abscess cavity $(2.0$ by $0.3 \mathrm{~cm}$.). The brain abscess lay in the subjacent cortex but somewhat eccentrically placed in relation to the subdural abscess and not communicating with it (Plate VIII c). The brain abscess measured about $6 \mathrm{~cm}$. in diameter ; its capsule was firm, but not as thick as that of the subdural abscess. The subdural abscess was also removed, but much of the subdural membrane over the peripheral part of the exposed brain was not disturbed because of its dense adherence to the subjacent cortex.

After this operation the patient was increasingly drowsy, so next day the wound was reopened and a small amount of clot removed, scarcely enough to account for her symptoms. On May 4 she suddenly became more alert and thereafter made a satisfactory recovery. At the time of her transfer to another hospital on May 14 her wound was healed and her general condition good, but her homonymous hemianopia and hemiplegia were still almost complete, and she was still emotionally labile and incontinent of urine. When last seen in August, 1947, she was walking but otherwise her hemiplegia had not improved, and she had had one fit.

In this case the sequence of events and the findings at operation leave little doubt that this patient had purulent pachymeningitis soon after she developed osteomyelitis of the skull. With systemic penicillin, and without any operative treatment other than aspiration of subgaleal pus, her hemiplegia recovered and she was free from symptoms for four weeks, when she developed a brain abscess. At operation the remains of the purulent pachymeningitis were seen in the form of a thick opaque membrane or granuloma, densely adherent to the dura and to the underlying cortex, and in the centre of this mass was a collapsed abscess cavity. The brain abscess was adjacent to the subdural abscess but did not communicate with it.

It is probable that the brain abscess arose after the purulent pachymeningitis and as a sequel to it for when she came under our care the only active source of infection found outside the brain was the very chronic collapsed abscess in the subdural space. The case illustrates the difficulties and dangers of suppressive treatment of purulent pachymeningitis with penicillin.

The following case emphasizes the same dangers and also indicates the need for obtaining ventriculographic proof that the patient is free from a space-occupying lesion before discharging him from hospital.

Case 7. Ethmoidal sinusitis and frontal osteomyelitis. Left frontal extradural, right frontal subdural collection of pus (ancerobic streptococcus). Drainage of both collecotions. Satisfactory progress under prolonged penicilliri treatment. Sudden death from left frontal cerebra P $_{\mathrm{D}}$ abscess five months after onset. (R.I. No. 57342/46.)

A boy, aged 12 years, was admitted to the Radcliffe Infirmary on May 1, 1946, with no other history tharb having struck his head against a tractor two days before From then onwards he complained of pain in his leff. temple. On the following day he had a number of right-sided focal epileptic attacks and developed signs of meningitis.

On admission he was conscious but obviously suffering from intolerable headache. Temperature and pulse rate were raised, and meningism was present. Both temporal regions were œdematous, and he had a little trismus, mild papillodema, and slight left-sided hemiparesis. Radiographs of the skull showed only opaque ethmoidal air cells. The lumbar cerebrospinal fluid was under $260 \mathrm{~mm}$. pressure, contained 27 cells per c.mm., and $35 \mathrm{mg}$. of protein per $100 \mathrm{c.cm}$. and was sterile.

Burr-holes revealed a subdural collection of pus confined to the right frontal lobe and the presence of extradural pus in the left frontal region ; the left subdural space was not explored. Two rubber tubes were inserted into the right frontal subdural space, and one into the left extradural space, and he had 8,000 units of penicillin given through each tube at four- or fivehourly intervals for nine consecutive days; that is, 270,000 units intradurally, and 13,000 units extradurally. He also had 240,000 units of intramuscular penicillin daily for four weeks $(6,720,000$ units), and a daily dose of $6 \mathrm{~g}$. of sulphadiazine for 25 days $(150 \mathrm{~g}$.). The organism found both in the subdural and in the extradural pus was an anærobic streptococcus. 
He made a rapid recovery, but on May 14 he had a peculiar attack of vomiting, incontinence, headache, and pallor, possibly an epileptiform manifestation. After this he was noticed to have developed papillœdema and some weakness on the right side, whereas his original slight left-sided hemiparesis had subsided by that time. Four weeks after admission a cisternal encephalogram was performed which showed small, non-displaced ventricles. Penicillin treatment was then stopped.

By June 15 his bifrontal burr-hole wounds had not quite healed, in fact there was by now an increasing purulent discharge, growing anærobic streptococci and Staphylococcus aureus. He had another attack, this time with profound and protracted stupor, followed by a series of right-sided focal epileptic attacks. His wounds were excised, and only now he was found to have frontal osteomyelitis. The macroscopically diseased areas around the burr-holes were removed. The dura was opened and the subdural space on the left side was found to be obliterated by granulation tissue. He was again put on systemic penicillin after a gap of nineteen days (240,000 units in 24 hours), and this was continued for a further nine weeks. At the time of his discharge from hospital he had received 22.320 mega units of penicillin systemically.

He returned to his home on Aug. 20, three months and twenty days after his admission, all sinuses having healed, and without radiological evidence of osteomyelitis, and perfectly fit as it seemed. He had been apyrexial ever since the third week following the onset of symptoms, and we regarded the result as very satisfactory and the prognosis as good.

Six weeks after his discharge, however, we were informed that he had died at another hospital following a short illness, slightly over five months after his first symptoms. An autopsy revealed a fairly well-encapsulated abscess, the size of a large walnut, situated in the left frontal lobe.

In the absence of full information about the necropsy it is not certain that this patient had a suppressed loculated subdural abscess over the left frontal lobe; nevertheless the course of events suggests that this is probable. Two weeks after his right subdural and left extradural abscesses were treated he developed signs of a left hemisphere lesion. A cisternal encephalogram showed normal ventricles, which is a point more in favour of an early subdural abscess than of a cerebral abscess. One month later, because of further signs of a left hemisphere lesion, the dura over the left hemisphere was opened for the first time and the subdural space was found to be occupied by granulation tissue. His symptoms subsided with prolonged penicillin therapy, but six weeks after this ceased he died suddenly of a left frontal cerebral abscess.

Whether our interpretation of the pathological events is correct, or whether this boy had a left frontal abscess almost from the start, the case shows clearly the dangerous suppressive effect which penicillin may exert on incompletely diagnosed intracranial infection. Such treatment should be controlled by accurate diagnosis of the intracranial pathology, and this can be achieved only by repeated ventriculography.

\section{Summary of Results}

The results of treatment (Tables VI and VII) show that only the patients who received adequate penicillin therapy by systemic and subdural routes recovered. Seven of the ten fully treated cases recovered, but three of these had loculated subdural abscess and one other had subdural abscess and cerebral abscess within a few weeks of the onset of purulent pachymeningitis. Thus, treatment is far from being a simple matter.

One of the seven survivors, a soldier from overseas, was observed for only three months after all trace of infection had subsided. The remaining six have been observed for periods of six months to four years from the time of recovery from the acute symptoms. In five of the six signs of cortical paralysis of one hemisphere had been complete, in one incomplete. In five of the six recovery from hemiplegia and sensory loss was virtually complete. Recovery from homonymous hemianopia was complete in four, incomplete in two. In the four patients who had aphasia, recovery of speech was complete.

Infrequent fits occurred some months after the acute stage in four of the six patients ; these seem to have been controlled by phenobarbitone. Recovery of intellectual function appeared to be fairly good, and all six patients were at work when last heard from ; however, in the case of the schoolboy (Case 3 ) it is doubtful whether intellectual recovery was up to the level of his previous standard.

Ventriculography, which was done after recovery in four of the six patients, showed some dilatation of the lateral ventricles (Fig. 3), and in one case comparison with a previous ventriculogram taken in the acute stage showed that the dilatation had taken place fairly rapidly during the course of the disease.

Treatment.-Table VIII summarizes the treatment given in the ten cases for which adequate supplies of penicillin were available. Although seven of our patients recovered we are far from feeling that our methods of treatment have reached finality.

Early Diagnosis.-Early recognition and treatment of purulent pachymeningitis is clearly of first importance. For anyone familiar with the syndrome produced by the disease, diagnosis should not be difficult. In any case of doubt, exploratory 
burr-holes should be made, several if necessary, and the subdural space should be carefully examined, by depressing the brain, for the presence of pus. The associated lesions, including extradural abscess, cerebral abscess, and purulent thrombosis of the venous sinuses, may not be so easy to recognize clinically; where doubt exists the appropriate exploration should be made, and ventriculography and arteriography should be employed as required.

When there is an extradural abscess the surgeon may be faced with the problem, should he open the dura through an infected field? In the past we avoided doing this, but now with the aid of penicillin the risks of setting up leptomeningitis or other intradural infection are small. It must be very rare, if indeed it ever happens, that extradural abscess causes complete sensori-motor hemiplegia, homonymous hemianopia, and aphasia. If such symptoms exist, operative exploration should not stop short at emptying an extradural abscess ; the subdural space should also be examined by opening the dura, if necessary through an infected field ; in that case coarse contamination of the intradural structures should be reduced to a minimum, penicillin should be applied at the site of the dural opening, and a prophylactic dose of penicillin should be injected into the lateral ventricle or lumbar subarachnoid space.

Systemic Penicillin.-All the bacteria so far encountered have been of groups sensitive to penicillin, and intensive systemic penicillin therapy should be begun without waiting for operative proof of the presence of infection, for our most

TABLE VIII

SUMMARY OF TREATMENT IN TEN FULLY TREATED CASES

\begin{tabular}{|c|c|c|c|c|c|c|c|c|c|c|c|}
\hline \multirow{2}{*}{$\begin{array}{c}\text { Case } \\
\text { No. } \\
\text { in } \\
\text { text } \\
\text { and } \\
\text { year }\end{array}$} & \multicolumn{8}{|c|}{ Total penicillin given } & \multirow{2}{*}{$\begin{array}{c}\text { No. } \\
\text { of } \\
\text { opera- } \\
\text { tions }\end{array}$} & \multirow[b]{2}{*}{ Result } & \multirow[b]{2}{*}{ Remarks } \\
\hline & $\begin{array}{l}\text { Sys- } \\
\text { temic } \\
\text { M.U. }\end{array}$ & Days & $\begin{array}{l}\text { Sub- } \\
\text { dural } \\
\text { M.U. }\end{array}$ & Days & $\begin{array}{l}\text { Into } \\
\text { C.S.F. } \\
\text { M.U. }\end{array}$ & Days & $\begin{array}{l}\text { Other } \\
\text { route }\end{array}$ & Days & & & \\
\hline $\begin{array}{l}2 \\
1943\end{array}$ & $\begin{array}{l}1.8 \\
0.7\end{array}$ & $\begin{array}{r}18 \\
9\end{array}$ & $\begin{array}{c}0 \cdot 153 \\
\cdots\end{array}$ & $\begin{array}{l}14 \\
\cdots\end{array}$ & $\begin{array}{c}0 \cdot 16 \\
\cdots\end{array}$ & $\begin{array}{l}16 \\
\cdots\end{array}$ & $\begin{array}{l}\text { Local } \\
\text { sinus }\end{array}$ & $\begin{array}{l}. . \\
. .\end{array}$ & $\begin{array}{l}2 \\
\cdots\end{array}$ & Recovered & .. \\
\hline $\begin{array}{l}5848 \\
1943\end{array}$ & $2 \cdot 77$ & 20 & 0.045 & 8 & 0.032 & 8 & .. & .. & 2 & Died & P.M. 234, 1943 융 \\
\hline $\begin{array}{l}7048 \\
1943\end{array}$ & $\begin{array}{l}2.025 \\
0.675\end{array}$ & $\begin{array}{r}21 \\
5\end{array}$ & $\begin{array}{l}. . \\
\ldots\end{array}$ & $\begin{array}{l}\cdots \\
\cdots\end{array}$ & $\begin{array}{c}0.0075 \\
\cdots\end{array}$ & $\begin{array}{l}4 \\
\cdots\end{array}$ & $\begin{array}{l}\text { Local } \\
\text { sinus } \\
0.0035\end{array}$ & $\begin{array}{l}. \\
\ldots\end{array}$ & $\begin{array}{l}3 \\
\cdots\end{array}$ & Recovered & .. \\
\hline $\begin{array}{l}3 \\
1944\end{array}$ & $\begin{array}{l}1 \cdot 08 \\
1 \cdot 44 \\
1 \cdot 10\end{array}$ & $\begin{array}{r}9 \\
9 \\
11\end{array}$ & $\begin{array}{c}0.140 \\
0.047 \\
\ldots\end{array}$ & $\begin{array}{c}6 \\
6 \\
\cdots\end{array}$ & $\begin{array}{l}0 \cdot 445 \\
\ldots \\
\ldots\end{array}$ & $\begin{array}{l}54 \\
\cdots \\
\cdots\end{array}$ & $\begin{array}{l}\ldots \\
\cdots \\
.\end{array}$ & .. & $\begin{array}{l}4 \\
. . \\
\cdots\end{array}$ & Recovered & .. \\
\hline $\begin{array}{l}4 \\
1945\end{array}$ & $\begin{array}{l}2 \cdot 24 \\
2 \cdot 24\end{array}$ & $\begin{array}{r}7 \\
14\end{array}$ & $\begin{array}{l}0.448 \\
0.216\end{array}$ & $\begin{array}{l}7 \\
6\end{array}$ & $\begin{array}{c}0 \cdot 153 \\
\ldots\end{array}$ & $\begin{array}{l}21 \\
\cdots\end{array}$ & $\begin{array}{l}0 \cdot 224 \\
\text { extra- } \\
\text { dural }\end{array}$ & $\begin{array}{l}7 \\
\ldots\end{array}$ & 7 & Recovered & .. \\
\hline $\begin{array}{l}62110 \\
1946\end{array}$ & $\begin{array}{r}1.44 \\
12.00 \\
0.48 \\
1.92\end{array}$ & $\begin{array}{r}6 \\
25 \\
2 \\
4\end{array}$ & $\begin{array}{c}0.448 \\
\ldots \\
\ldots \\
\ldots\end{array}$ & $\begin{array}{l}14 \\
\cdots \\
\cdots \\
\therefore\end{array}$ & $\begin{array}{c}0 \cdot 158 \\
\ldots \\
\ldots \\
\ldots\end{array}$ & $\begin{array}{l}15 \\
\cdots \\
\cdots \\
.\end{array}$ & $\begin{array}{l}\because \\
\therefore \\
.\end{array}$ & $\begin{array}{l}. \\
\therefore \\
\cdots\end{array}$ & $\begin{array}{l}4 \\
\ldots \\
\cdots \\
.\end{array}$ & Died & $\begin{array}{l}\text { Osteoplastic flap } \\
\text { for removal of } \\
\text { abscess }\end{array}$ \\
\hline $\begin{array}{l}7 \\
1946\end{array}$ & $\begin{array}{l}6 \cdot 72 \\
6 \cdot 24 \\
9 \cdot 28\end{array}$ & $\begin{array}{l}28 \\
26 \\
29\end{array}$ & $\begin{array}{l}0 \cdot 216 \\
\ldots \\
\ldots\end{array}$ & $\begin{array}{l}9 \\
\cdots \\
\cdots\end{array}$ & $\because$ & $\begin{array}{l}. . \\
\cdots\end{array}$ & $\begin{array}{l}0.216 \\
\text { extra- } \\
\text { dural }\end{array}$ & $\begin{array}{l}9 \\
\cdots \\
\cdots\end{array}$ & $\begin{array}{l}4 \\
\cdots \\
\cdots\end{array}$ & Died & .. \\
\hline $\begin{array}{l}6 \\
1947\end{array}$ & $\begin{array}{l}? \text { (elsew } \\
7 \cdot 44\end{array}$ & $\begin{array}{c}\text { here) } \\
31\end{array}$ & . & .. & $\therefore$ & .. & .. & .. & 3 & Recovered & $\begin{array}{l}\text { Subdural abscess } \\
\text { remo ved with } \\
\text { cerebral abscess }\end{array}$ \\
\hline $\begin{array}{l}66643 \\
1946\end{array}$ & $\begin{array}{r}12 \cdot 48 \\
6.72\end{array}$ & $\begin{array}{l}26 \\
28\end{array}$ & $\begin{array}{c}0.352 \\
\ldots\end{array}$ & $\begin{array}{l}11 \\
\cdots\end{array}$ & $\begin{array}{c}0 \cdot 20 \\
\ldots\end{array}$ & $\begin{array}{l}1 \\
. .\end{array}$ & $\begin{array}{l}\cdots \\
\cdots\end{array}$ & $\begin{array}{l}. . \\
\cdots\end{array}$ & $\begin{array}{l}4 \\
\cdots\end{array}$ & Recovered & .. \\
\hline $\begin{array}{l}67032 \\
1947\end{array}$ & $24 \cdot 48$ & 51 & 0.448 & 14 & 0.472 & 46 & .. & .. & 5 & Recovered & .. \\
\hline
\end{tabular}


recent cases suggest that when penicillin is given promptly the disease is somewhat milder. As our experience has grown we have increased both the dose and the duration of systemic penicillin (Table VIII) and we now recommend not less than 100,000 units three-hourly, at least until the organism has been identified and its in-vitro sensitivity to penicillin estimated. Even larger doses might be required if the organism proved to be relatively resistant ; and, indeed, it is clearly an advantage to maintain a high level of penicillin in all parts of the subdural space from the earliest possible moment. Systemic penicillin should be continued for at least eight weeks if there is osteomyelitis of the skull or facial bones, if purulent thrombosis of the venous sinuses is suspected, or if there is any suspicion of the formation of a loculated subdural abscess.

The patient should be under close medical observation at the time when penicillin is stopped and for the next four to six weeks, in order that recrudescence of infection in the subdural space, in the brain, or in the skull may be promptly recognized and treated.

Subdural Penicillin.-Theoretically it might be possible in the early stage of purulent pachymeningitis to treat the infection of the subdural space with massive doses of systemic penicillin $(200,000$ units two-hourly), with the object of obtaining high levels of penicillin in all parts of the subdural space. The experience of Case 6 does not favour the experiment, but the amount of penicillin administered in the early stage was probably no more than standard dosage for the general run of pyogenic infections. Once the subdural suppuration is established even massive doses of penicillin may not eradicate the infection: Case 7, who had 22 mega units systemically in thirteen weeks, died of a cerebral abscess six weeks after penicillin was stopped.

Penicillin solution by the subdural route probably has the advantage of acting mechanically as well as by providing a high level of penicillin. In our most successful case (Case 2) very large quantities of dilute penicillin solution were injected into the subdural space for fourteen days and the infection cleared up without subdural loculation or any other complication. The in-dwelling subdural catheters should be spread as widely as possible over the convex surface of the cerebral hemisphere and their position should subsequently be ascertained by radiographs (Plate IV $b$ ). If they are not satisfactorily placed they can be altered by manipulation, or additional tubes can be inserted at a further operation. As much penicillin solution as the subdural space will hold should be injected through these tubes at three-hourly intervals, for the larger the quantity of fluid the more likely it is to spread to all parts of the subdural space and thus to prevent loculation. Withdrawal of ventricular or lumbar cerebrospinal fluid may enable larger amounts to be instilled into the subdural space. Within certain limits the concentration of the solution is probably less important than the bulk; at present we recommend 500 units per c.cm., but further work is required to establish the optimal concentration.

In the early stages of the disease the subdural pus is not circumscribed, though it is not found in all parts of the subdural space, and the aim should be to flood the whole space with penicillin solution. It might be a good thing to pass a catheter on the healthy as well as on the affected side, when the disease is unilateral, though we have not yet done this. Likewise in the acute stage before loculation we have never passed a catheter over the medial surface of the hemisphere, which is the favourite place for loculation of pus. Probably a catheter for subdural penicillin alongside the posterior half of the falx at a fairly early stage of the illness would diminish the frequency of loculated subdural abscess, but this also we have not yet done before the pus has become loculated.

Subdural Abscess.-When subdural abscess is suspected it should be sought for by passing a brain needle through one or more burr-holes. The favourite site for abscess, alongside the posterior part of the falx or on the surface of the adjacent tentorium, can best be explored through a series of parasagittal parietal burr-holes, the needle being directed downwards and medially through the parietal lobe - a trans-cerebral exploration of the subdural space. When the abscess is found it should be aspirated, and replaced by a large dose of penicillin $(100,000$ units in $2 \mathrm{c.cm}$. saline) and $2 \mathrm{c.cm}$. of thorotrast. Radiographs should then be taken, especially tangential projections, to determine the situation and extent of the abscess. On subsequent days we have treated the abscess by daily intermittent aspiration (Case 3) or, preferably, by continuous drainage through an in-dwelling catheter (Case 4), and daily instillation of penicillin for at least five days. The in-dwelling catheter is usually best inserted between the falx and medial border of the posterior part of the cerebral hemisphere through a dural incision in the angle between the posterior end of the sagittal sinus and the adjacent lateral sinus of the appropriate side. Our limited experience suggests that when the infection has spread from the mastoid process the loculated subdural abscess may be difficult to treat. In such cases it might be better to insert one catheter beneath the lateral edge of the hemisphere, but it 
is probable that the parasagittal catheter will also be required. Great rise of intracranial pressure may hinder insertion of this catheter, in which case a brain needle may be left in the abscess cavity for twenty-four hours, as in Case 3.

General Management.-The severity of illness in these patients may be extreme for three to four weeks. Stupor may interfere with swallowing so that the risk of aspirating fluids into the trachea and bronchi is considerable. Moreover, as Williams (1944) has pointed out, some of these patients with pansinusitis may have some pre-existing lung infection, and one of our patients developed an interlobar empyema or lung abscess (anærobic streptococcus) at the same time as purulent pachymeningitis. There must be the utmost care in administering fluids and for several days feeding should usually be by in-dwelling stomach tube. If respiratory symptoms arise the patient should be nursed with his head low, by raising the foot of the bed on blocks, even though his intracranial pressure is already raised. Blood transfusions are valuable in the acute stage of the infection. As fits are not infrequent, both in the acute stage and subsequently, phenobarbitone should be given for some months. Careful day-to-day clinical assessment and frequent examination of the pressure and cellular content of the lumbar cerebrospinal fluid are required in order to detect the onset of subdural loculation and other complications.

Operations.-The operative procedures are not usually extensive, a point of considerable importance in patients who are so very ill; but, as Table VIII shows, each patient had several operative sessions as many as seven in one case. Burr-holes are required for detection of pus and insertion of penicillin tubes, or for ventriculography ; bone may have to be removed for osteomyelitis of the skull or drainage of extradural abscess. In some cases operations on the paranasal sinuses or mastoid may be required, or purulent clots may need to be removed from the venous sinuses. Carotid arteriography may furnish useful information.

Until the technique of handling these subdural infections is further improved it seems to us that the best way of obtaining recovery is by frequent minor operative procedures designed to discover foci of pus. and to apply penicillin to the subdural space and to any subdural abscesses which may have formed.

If a cerebral abscess develops it should be treated by excision through an osteoplastic flap when the residual subdural infection can also be dealt with Case 6).

Subarachnoid and Ventricular Penicillin.-The leptomeningitis varies in its severity, and subarachnoid or ventricular penicillin is not required unless the cerebrospinal fluid indicates a frank bacterial infection. However, when the medial and inferior parts of the subdural space are being explored for abscess across the cerebral hemisphere, or when the subdural space over the convexity is being explored through a field contaminated by the presence of osteomyelitis or extradural abscess, there must be a risk of setting up leptomeningitis or ventriculitis. This can be overcome by a single prophylactic injection of penicillin into the ventricle. For all purposes a dose of 10,000 to 15,000 units will give an adequate concentration of penicillin in the cerebrospinal fluid for twenty to twenty-four hours ; large doses are not only unnecessary, they may also be harmful (Smith and others, 1946).

Osteomyelitis.-Spreading osteomyelitis of the skull is present in the majority of cases and is sometimes inconspicuous, particularly when penicillin has been given early in the illness. If not obvious it should be repeatedly looked for by radiographs during the course of the illness. With systemic penicillin maintained for eight to twelve weeks it seems likely that in most cases there will be no need to remove large areas of skull. The osteomyelitis will either subside without operation, as in Case 3,0 or with limited removal of pus and sequestra, as in Case 2. With penicillin it should rarely be necessary to undertake a massive removal of bone in the acute stage, as used to be done (Plate VI a). However, if after the subdural infection has been overcome? any focus of sequestration and suppuration remains in the skull it should be removed, for such foci may harbour living bacteria for long periods and are apt to produce recrudescence of cranial or intracranial infection once penicillin is stopped. In cases treated with penicillin the radiographs may show areas of rarefaction which suggest foci of pus in the bone where none exist (Fig. 4).

Residual Infection.-Three of our ten cases (Cases 6,7 , and one other) developed further intracranial infection at a time when they appeared to have made a satisfactory recovery. Two had a cerebral abscess and the third probably had a medial loculated subdural abscess. In each case the symptoms were probably kept in check for a time by systemic penicillin, for they only appeared after the drug had been withdrawn. While in one of these cases the symptoms cleared up completely and permanently with a further and prolonged course of penicillin systemically, in the other two cases the subdural abscess was only "suppressed" by the penicillin and the patient subsequently developed a cerebral abscess. In view of the frequency of residual 
infection we consider that the right course in all patients who have made a clinical recovery from pachymeningitis is to ensure, as far as is possible by means of ventriculography before the patient leaves hospital, that no focus of intracranial infection remains. If the ventricles are perfectly symmetrical it is reasonably certain that no abscess remains. We would stress again the advisability of keeping the patient under close observation for some weeks after penicillin has been stopped.

The Primary Focus.-In some cases it will be necessary for the otologist to deal radically with the primary infection in the paranasal sinuses or petrous bone. If possible, this operative treatment should be deferred for some months after the pachymeningitis, and systemic penicillin should be administered for some days before the operation.

Prophylaxis.-It seems likely that the incidence of purulent pachymeningitis, uncommon though it may be, could be considerably reduced with adequate prophylaxis. According to Turner and Reynolds (1931, p. 256) the condition arises most commonly in cases of chronic, or acute superimposed on chronic pansinusitis or mastoiditis, after some operative interference, sometimes no more than simple puncture of the maxillary sinus. As McKenzie (1913) said, "What seems to be an irreproachable operation is followed by progressive osteomyelitis," and one otologist described it as "like setting fire to shavings." In view of the proved efficacy of penicillin in the treatment of both the osteomyelitis and the purulent pachymeningitis there can be little doubt that these complications of sinus and mastoid surgery could be prevented by adequate doses of systemic penicillin for a few days before and after surgical intervention.

\section{Summary}

1. In the last twenty years we have had thirtythree cases of spreading purulent pachymeningitis. Of these, twenty-two followed pansinusitis, seven followed mastoiditis, and four were secondary to distant foci of infection. Spreading osteomyelitis of the skull, with or without osteomyelitis of the facial bones, was associated with purulent pachymeningitis in at least twenty-six cases; its presence is apt to be overlooked. Other associated lesions were : extradural abscess in sixteen cases; cerebral abscess in nine cases ; severe leptomeningitis in seven cases, the remainder showing only a mild leptomeningeal reaction; thrombosis of the dural venous sinuses and/or the cerebral veins, sometimes purulent, in seven cases ; abscess of the lungs in two cases; and in one case obstruction of the common carotid artery in the neck, discovered by accident during cerebral angiography, and probably due to thrombosis.

2. Of twenty-seven cases in which the bacteriology is recorded the subdural infection was due to streptococci in twenty-five cases (combined in one case with Staphylococcus aureus), to Staphylococcus aureus alone in one case, and to pneumococcus in one case in which there was also intense purulent leptomeningitis. The streptococci were grown in seventeen cases and were anærobic in ten, $\alpha$-hæmolytic in six, and $\beta$-hæmolytic in one. In our experience Staphylococcus aureus produces osteomyelitis of the skull as frequently as the non$\beta$-hæmolytic groups of streptococci, but rarely spreads diffusely through the skull or produces purulent pachymeningitis as the non- $\beta$-hæmolytic streptococci do, though it frequently produces brain abscess. These differences of behaviour of the two groups of bacteria are not explained.

3. In one case the causal anærobic streptococcus was not inhibited in vitro by 5 units per c.cm. of penicillin. In three other cases the streptococcus was completely inhibited by 0.04 units per c.cm. of penicillin or less. In all ten cases which were fully treated with penicillin (non- $\beta$-hæmolytic streptococci eight, Staphylococcus aureus one, and pneumococcus one) the clinical response indicated that the infecting organism was sensitive to penicillin.

4. The clinical picture of purulent pachymeningitis is characteristic and corresponds to a diffuse paralysis of the cortex of one cerebral hemisphere associated with rise of intracranial pressure.

5. Before the introduction of penicillin eighteen patients were treated by removal of variable amounts of osteomyelitic skull and attempts to drain the subdural space; all died. When limited amounts of penicillin became available five patients were treated by local instillation of penicillin into the subdural space and all of these died.

6. Ten cases have been fully treated with penicillin by systemic, subdural, intraventricular, and subarachnoid routes. Of these seven recovered. In six of these patients the late result is known from six months to four years after recovery from acute symptoms ; in all except one, who had a cerebral abscess as well, the functional recovery is complete or almost complete, but four of the patients have infrequent fits.

7. Penicillin passes freely from the blood stream to the subdural space. In spite of this we found it necessary to instil penicillin solution directly into the subdural space. The details of this method are described. 
8. In seven of our ten fully-treated cases, after the diffusely spreading phase of the subdural space suppuration was overcome, the patient developed a loculated subdural abscess, and at a later stage in two of these cases there was abscess of the brain. The day-to-day assessment of these cases, and the early recognition and operative treatment of the complications (and of the associated lesions) are far from easy; these aspects are discussed in detail.

9. Purulent pachymeningitis most commonly follows operation for chronic pansinusitis or mastoiditis, and its incidence should be considerably reduced by maintaining an adequate concentration of penicillin in the blood before, during, and after these operations.

\section{REFERENCES}

Cairns, H. (1930). Proc. roy. Soc. Med., 23, (Sect. Otol.), 49.

--(1937). J. Laryng., 52, 589.

(1947). Brain, 70, 251.

, Calvert, C. A., Daniel, P., Northcroft, G. B. (1947).

Brit. J. Surg. War Surgery Supplement No. 1, p. 198.

—, and Russell, D. S. (1946). J. Path. Bact., 58, 649.
Dreyfuss, R. (1896). "Die Krankheiten des Gehirns und seiner Adnexe im Gefolge von Naseneiterungen." Jena.

Gilmour, J. R. (1941). J. Path. Bact., 53, 263.

Hempstead, B. E. (1944). Proc. Mayo Clin., 19, 480.

Kubik, C. S., and Adams, R. D. (1943). Brain, 66, 18.

Kuhnt, H. (1895). "Ueber die entzündlichen Erkrankungen der Stirnhöhlen und ihre Folgezustände." Wiesbaden.

McKenzie, D. (1913). J. Laryng., 28, 6.

Moniz, E. (1941). " Trombosis y otras Obstrucciones de las Carotidas." Salvat. Editores, S.A. Barcelona..

Penfield, W. G. (1924). Anat. Rec., 28, 173.

Robertson, W. F. (1900). "A Textbook of Pathology in Relation to Mental Diseases." Edinburgh. Clay. p. 285.

Sandusky, W. R., Pulaski, E. J., Johnson, B. A., $\frac{}{\bar{D}}$ Meleney, F. L. (1942). Surg. Gynec. Obstet. 75, 145.

Sherman, J. M. (1937). Bact. Rev., 1, 3. Smith, H. V., Duthie, E. S., and Cairns, H. (1946).
Lancet, 1, 185.

Turner, A. L., and Reynolds, F. E. (1931). "Intra- $\vec{O}$ cranial Pyogenic Diseases." Edinburgh. Oliver and Boyd.

Tutton, G. K., and Shepherd, W. H. T. (1948). In the press.

Weed, L. H. (1932). In "Cytology, and Cellular Pathology of the Nervous System." Edited by? Wilder Penfield. Vol. 2, p. 611 .

Williams, H. L. (1944). Proc. Mayo Clin., Hoebef $\vec{\omega}$ New York. 19, 474.

Williams, H. L., and Heilman, F. R. (1937). Otolaryng., Chicago, 25, 196.

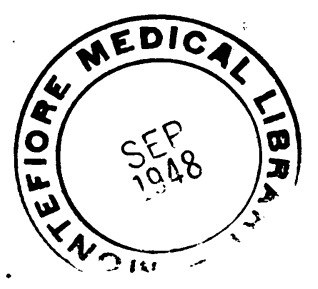

